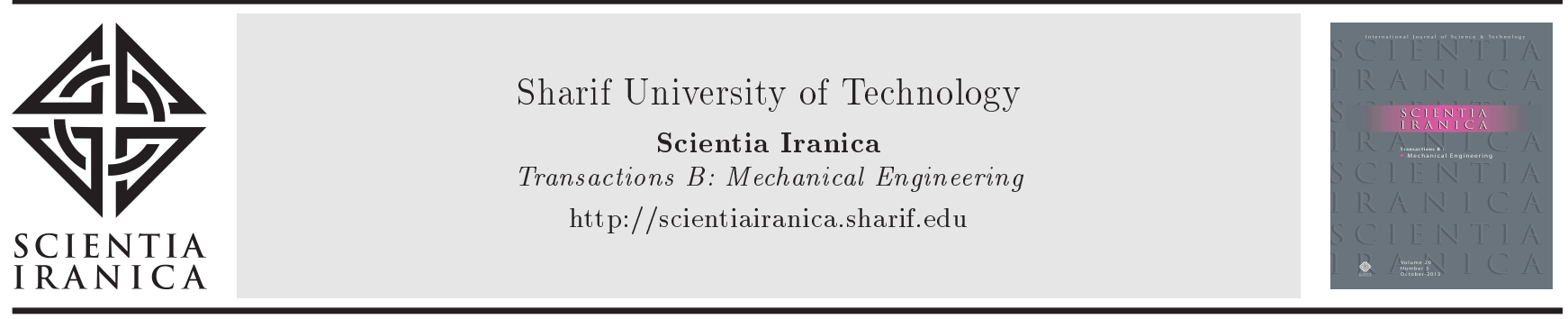

\title{
Solar assisted desiccant evaporative cooling system for office buildings in Iran: An annual simulation model
}

\author{
M. Ahmadzadehtalatapeh* \\ Department of Mechanical \& Marine Engineering, Chabahar Maritime University, Chabahar, 99717-56499, Iran.
}

Received 21 May 2016; received in revised form 14 September 2016; accepted 28 January 2017

\section{KEYWORDS}

Energy performance;

Building;

Indoor air;

Solar desiccant based

cooling system;

TRNSYS.

\begin{abstract}
In this research, the feasibility of solar assisted desiccant evaporative cooling system for office buildings was studied. An office building located in Chabahar, Iran, as a high cooling load demanding region, was considered as the case study. Different configurations as desiccant-based cooling systems were examined to determine the most appropriate configuration in terms of established indoor air conditions and required cooling energy. The configurations were simulated hourly, and the monthly mean values were determined. TRNSYS software was used for this purpose. The results indicated that the desiccant-based cooling system operating in the recirculation cycle with precooling Config. $\mathrm{E}$ has the potential to keep the indoor air conditions within the standard recommendations. In addition, it was shown that Config. E is the superior configuration in terms of the energy performance and can meet the cooling energy requirements of the space. The potential for providing the desiccant regeneration heat by the solar energy was also investigated. Three standard solar thermal panels were explored to propose the most proper array plant. The study showed that an array of solar panels, consisting of two rows of four unglazed solar thermal collectors, could meet the heat energy requirement by the regenerating process.

(C) 2018 Sharif University of Technology. All rights reserved.
\end{abstract}

\section{Introduction}

Iran is ranked fourth in the world in terms of hydrocarbon resources. However, because of the newly imposed regulations towards the actualization of the pricing rates, benefiting from the renewable energy resources has been one of the major priorities of the energy policy-makers of the country. To this end, the Renewable Energy Organization of Iran has recommended a strategic program under the five-year national development plan [1]. Based on the proposed plan, Iran is determined to provide $10 \%$ of its elec-

*. Tel.: +985431272137

E-mail address: m_ahmadzadeh56@yahoo.com tric power demand from the renewable resources by 2025 [2].

Based on the statistics, the final energy consumption annual growth rate in Iran is $6.4 \%$ [3]. In addition, building sector is responsible for large portion of the total energy consumption in countries with about $40 \%$ [4]. It was also shown that, for buildings, the major energy-consuming section is the Heating, Ventilating, and Air Conditioning (HVAC) systems. Therefore, buildings' contribution to greenhouse gas emissions is significant. Therefore, energy conservation by application of renewable energy resources in buildings to lessen the problems of energy and environment seems to be essential.

Solar, wind, biomass, and geothermal energy as the main renewable energy resources have the potential to be used in Iran. Iran benefits from rich solar energy with the mean solar radiation of $2000 \mathrm{kWh} / \mathrm{m}^{2}$ year [2]. 


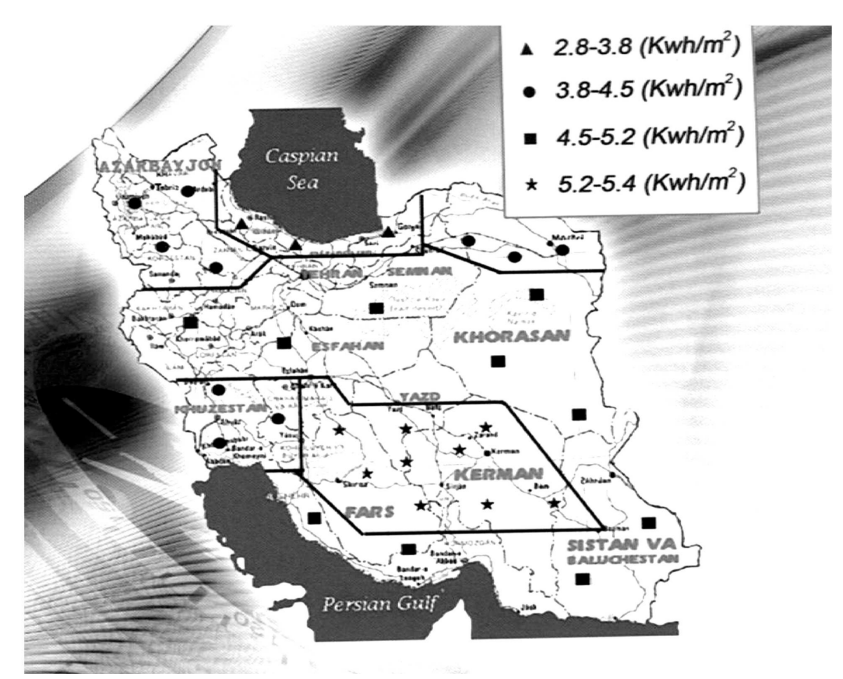

Figure 1. Solar energy map of Iran [2].

There are 2800 sunny hours in a year with up to 3200 hours in the central regions of the country $[5,6]$. Therefore, Iran's climate condition encourages the researchers and designers to implement the solar energyrelated technologies to improve the performance of the HVAC systems. Figure 1 illustrates Iran's solar map.

Solar Assisted Desiccant Cooling System (SDCS) has the capability of achieving this objective and is proposed as an alternative to conventional vapor compression HVAC systems. It is expected to achieve improvements in energy efficiency and indoor air quality because of its environmentally-friendly characteristics. SDCS does not need ozone-depleting refrigerant and benefits from the free solar energy and natural sorption dehumidifier.

A number of research studies on the SDCS have been reported theoretically and experimentally [7-22]. For instance, Li et al. [7] investigated the performance of two-stage desiccant cooling/heating system powered by solar energy. The study showed that the twostage desiccant cooling system can totally handle the humidity load for 63 days $(51.7 \%)$, and about $49.0 \%$ can be handled by the solar energy for seasonal total heating load. Mavroudaki et al. [8] studied the feasibility of the solar powered single-stage desiccant cooling for the Europe. Based on this research, application of the system was recommended for southern Europe and most of central Europe. In another research, the application of a solar assisted heating and desiccant cooling system was examined for domestic buildings [9] A solar assisted pre-cooled hybrid desiccant cooling system was investigated and recommended for Pakistan by Khalid et al. [10]. In this study, four modes of the cooling purposes were tested. Bourdoukan et al. [11] investigated solar desiccant plant equipped with heat pipe tubes. In another research study, the capability of a solar desiccant evaporative cooling was investigated for commercial buildings under the Australia climate condition [12]. Enteria et al. [13] explored the effect of Silica-Gel $\left(\mathrm{SiO}_{2}\right)$ and Titanium Dioxide $\left(\mathrm{TiO}_{2}\right)$ as the Desiccant Wheel (DW) coating materials on the performance of the DWs. In order to improve the performances of SDCS, solar hybrid desiccant cooling systems were examined by Fong et al. [14] under different climate and loading conditions. In this investigation, three hybrid designs were recommended for full fresh air design and another three for return air design. The potential for designing and operating a Desiccant Cooling System (DCS) without any thermal backup was also investigated in Australia [15].

Solar energy in Iran is used normally for power generation and hot water supply purposes. However, utilization of solar energy for space cooling purposes has not been considered strongly in the country so far. Furthermore, research studies based on the Typical Meteorological Year (TMY) weather data to estimate the yearly performance of the so-called SDCS are very limited.

For this purpose, this research was conducted, and its major aim is to investigate the feasibility of SDCS for south and southeast regions of Iran's climate conditions. This research was performed to evaluate the possible effects of the SDCS on the established indoor air conditions and energy consumption of an Office Building in Chabahar Maritime University (OBCMU), Iran. The considered building is located in the southeast of the country. (Note: south and southeast regions of the country are considered as high cooling load demanding regions.)

\section{Research methodology}

The present research study explores the feasibility of SDCS for office buildings in a high cooling load demanding region of Iran. To this end, the established indoor air conditions of the considered space were derived through simulation in TRNSYS studio, and then the results were presented. Then, six proposed configurations for DCS were examined in terms of the provided indoor air and extra required cooling energy. The simulation process will be discussed in the following sections.

In Section 4, the space performance will be presented in terms of indoor air conditions and required cooling energy. In Sections 5 and 6, the desiccantbased configurations and their simulation process will be explained, respectively. The array of solar thermal collectors will be presented in Section 7 , and the results and discussion will be presented in Section 8 .

\section{Simulation using TRNSYS}

TRNSYS is one of the most important transient simulation software products of thermal systems employed 
by the researchers and mechanical designers to validate the new energy-related concepts. TRNSYS software as a complete simulation environment is capable of modelling simple domestic systems and design and simulation of buildings equipped with alternative energy systems [23]. The software library consists of standard equipment being used in the industry; however, the software enables users to define and add the nonstandard equipment to the library as a new component.

\section{TRNSYS simulation of the space}

The selected office space (OBCMU) is the control room of the Information Technology Center (ITC) building and is located on the second floor of the building. Figure 2 shows the building overview.

In order to obtain the existing indoor air conditions and the required cooling load, the space was simulated by the TRNSYS studio. The OBCMU was considered as a single thermal zone (Type 54a), and the required technical data for the Type 54a component were defined. The simulation layout for the existing space (space without the desiccant-based configuration) is illustrated in Figure 3. The functions of the components in Figure 3 are explained in Table 1.

\section{Space integrated with the Desiccant Cooling System (DCS)}

\subsection{DCS performance}

As a general performance description, a DCS is a dehumidifier consisting of a rotary DW coated with a

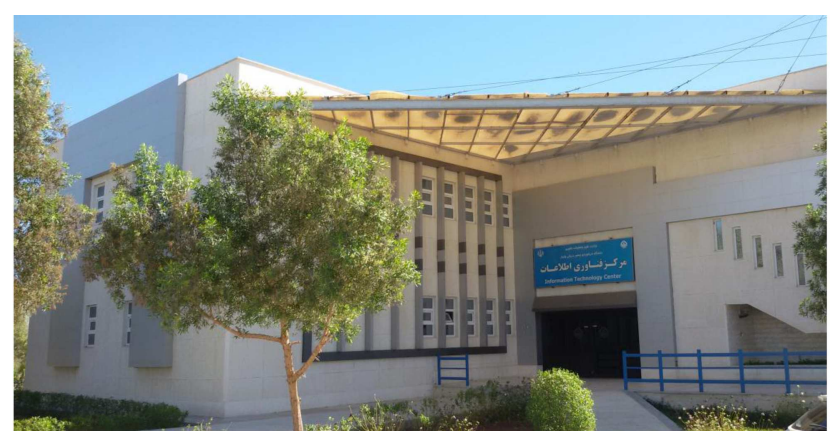

Figure 2. OBCMU overview.

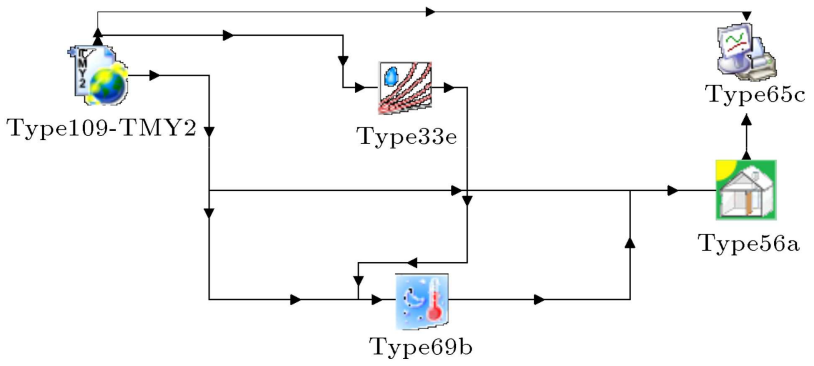

Figure 3. TRNSYS components to simulate responses of the OBCMU. liquid or solid desiccant material, such as silica gel, lithium chloride, and lithium bromide. The main task of the DW is to capture the moisture content of the moist supply air before entering into the conditioned space. In addition, for continuous operation of the DW, the desiccant dehumidifier needs to be regenerated. In the regeneration process, absorbed water vapor is driven out of the desiccant material to make the wheel dried enough to absorb moisture in the next cycle. The regeneration process can be performed by heating the desiccant material to its regeneration temperature. The renewable energy resources, such as solar energy, could provide heat energy required for the regeneration process.

To improve the performance of DCS, some other energy converting units, such as direct evaporative cooler, indirect evaporative cooler, and Energy Wheel (EW), were also recommended to be employed in the DCS. Figures 4 and 5 illustrate the schematic of a DW and its general performance, respectively.

Different configurations, consisting of a DW, an EW, a direct and indirect evaporative cooling units, were recommended and available in the reports. In this study, six different configurations commonly proposed for the HVAC systems were examined to determine the most proper design in terms of established indoor air conditions and required extra cooling energy for the Iran climate condition. The configurations are:

- Config. A: Desiccant-based evaporative cooling system operating in ventilation cycle (Pennington cycle);

- Config. B: Desiccant-based evaporative cooling system operating in recirculation cycle;

- Config. C: Desiccant-based evaporative cooling system operating in Dunkle cycle;

- Config. D: Desiccant-based evaporative cooling system operating in modified ventilation cycle;

- Config. E: Desiccant-based evaporative cooling system operating in modified recirculation cycle with pre-cooling;

- Config. F: Desiccant-based evaporative cooling system operating in ventilation cycle with double series EW.

More details on the configurations and simulation process will be explained in the subsections below.

\subsection{Config. A: Desiccant-based evaporative cooling system operating in ventilation cycle (Pennington cycle)}

One of the configurations, which is applied for DCS, is desiccant-based evaporative cooling system operating in ventilation cycle, Config. A. In ventilation cycle, the process air is the fresh outdoor air, and the return air 
Table 1. The processes and functions in Figures 3, 16, 17, and 26.

\begin{tabular}{|c|c|c|}
\hline Code or label & Description of the component & Function \\
\hline$\frac{1}{\text { Type109-TMY2 }}$ & Region weather data & $\begin{array}{l}\text { This component reads TRNSYS TMY } 2 \\
\text { format weather file to determine the outdoor } \\
\text { condition. }\end{array}$ \\
\hline & Building (space) & $\begin{array}{l}\text { This component takes the inlet temperature, } \\
\mathrm{RH} \text {, and air flow to calculate the space } \\
\text { temperature and RH. }\end{array}$ \\
\hline & Ambient related data & $\begin{array}{l}\text { This component takes the ambient air data } \\
\text { and calculates the fictive sky temperature. }\end{array}$ \\
\hline & DW & $\begin{array}{l}\text { This component takes the inlet temperature, } \\
\mathrm{RH} \text {, and air flow to calculate the leaving } \\
\text { temperature and } \mathrm{RH} \text { for the supply and } \\
\text { return sides. }\end{array}$ \\
\hline Type220 & EW & $\begin{array}{l}\text { This component takes the inlet temperature } \\
\text { and humidity ratio to calculate the leaving } \\
\text { temperature and humidity ratio for the } \\
\text { supply and return sides. }\end{array}$ \\
\hline Type223 & Indirect evaporative cooler & $\begin{array}{l}\text { This component takes the inlet dry and wet } \\
\text { bulb temperatures to calculate the leaving } \\
\text { dry and wet bulb temperatures. } \\
\text { This component takes the inlet dry and wet } \\
\text { bulb temperatures to calculate the leaving } \\
\text { dry and wet bulb temperatures. }\end{array}$ \\
\hline Type224 & Desiccant heater & $\begin{array}{l}\text { This component takes the inlet temperature } \\
\text { and humidity ratio to calculate the leaving } \\
\text { temperature and humidity ratio. }\end{array}$ \\
\hline 282 & Solar thermal collector & $\begin{array}{l}\text { This component takes the inlet temperature } \\
\text { to calculate the leaving temperature and } \\
\text { delivered energy. }\end{array}$ \\
\hline 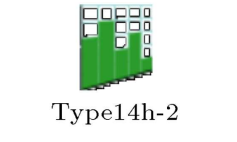 & Time controller & $\begin{array}{l}\text { This component controls the operating } \\
\text { hours. }\end{array}$ \\
\hline$\underbrace{[809]}_{\text {Equa }}$ & Equation & $\begin{array}{l}\text { This component is used for calculation } \\
\text { purposes. }\end{array}$ \\
\hline
\end{tabular}


Table 1. The processes and functions in Figures 3, 16, 17, and 26 (continued).

\begin{tabular}{ccl}
\hline Code or label & Description of the component & \multicolumn{1}{c}{ Function } \\
\hline & Psychrometric calculator & $\begin{array}{l}\text { This component takes any two properties of } \\
\text { moist air and calculates all other properties. }\end{array}$ \\
& Online plotter & $\begin{array}{l}\text { This component illustrates the simulated } \\
\text { data on the screen and saves them into a } \\
\text { specified file. }\end{array}$ \\
\hline
\end{tabular}

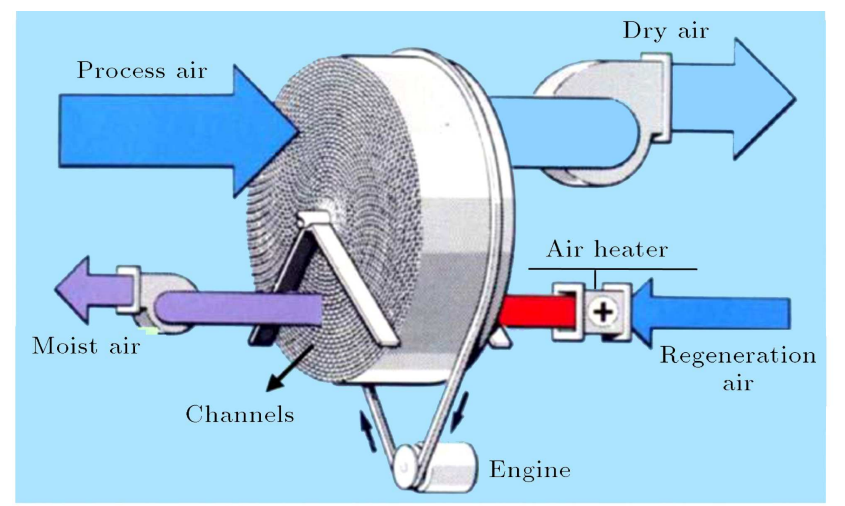

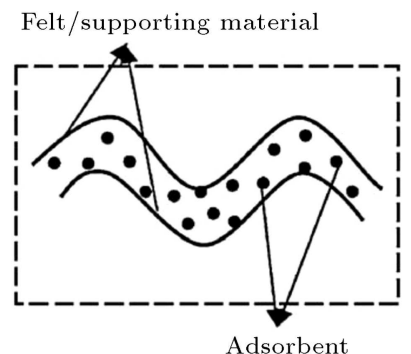

One channel

Figure 4. Schematic diagram of a rotary DW [24].

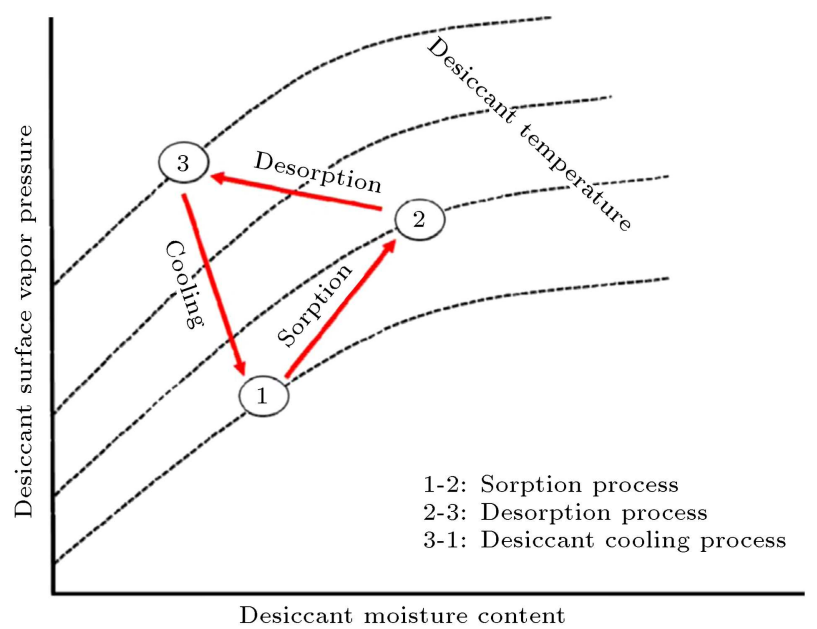

Figure 5. Dehumidification and regeneration process of a DW [25].

from the space is used as the regeneration process air, as illustrated in Figure 6.

As shown in Figure 6, in Config. A, the supply or process air passes through a DW, and its moisture is absorbed by the desiccant material, significantly. The process air temperature rises, and warm and dry air leaves the DW. The desiccant leaving air stream then passes through a rotary EW and is cooled by the sensible performance of the EW. An evaporative cooler was placed after the EW, and the EW leaving air passes through the evaporative cooler before entering into the conditioned space. The return air as the regeneration air passes through another evaporative cooler directly after leaving the conditioned space to serve as a heat sink to the rotary EW for cooling the process air. The EW leaving return air undergoes a heating source to reach a temperature suitable for the regeneration process in the DW. At this point, in order to reduce the heat consumption of regeneration process, a certain portion of the return air could bypass the heating source.

\subsection{Config. B: Desiccant-based evaporative cooling system operating in recirculation cycle}

To improve the cooling capacity of the explained ventilation cycle (Pennington cycle), the recirculation cycle was developed. As illustrated in Figure 7, in this cycle, the air stream passes through the energy units similar to the ventilation cycle; however, in the recirculation cycle, the return air from the space is used as the process air and the outdoor air is used as the regeneration air. Lacking fresh air is reportedly the main disadvantage of this cycle.

\subsection{Config. C: Desiccant-based evaporative cooling system operating in Dunkle cycle}

Dunkle proposed this configuration, and it is the combination of the recirculation cycle with an extra heat exchanger (EW). The additional EW was added 


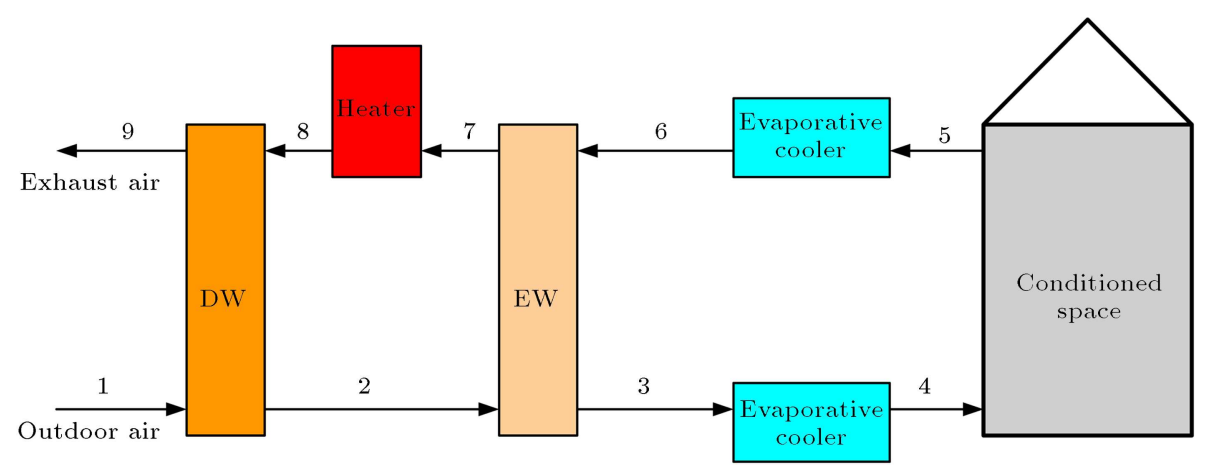

Figure 6. Desiccant-based evaporative cooling system operating in ventilation cycle (Pennington cycle) [26].

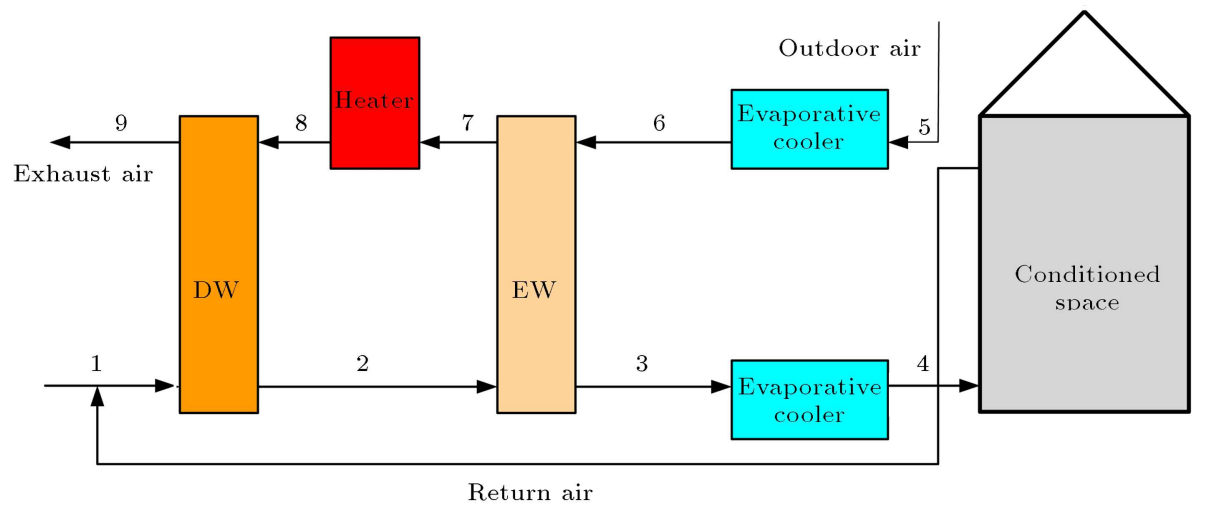

Figure 7. Desiccant-based evaporative cooling system operating in recirculation cycle [26].

to improve the performance of the system. Dunkle cycle employs the $100 \%$ recirculation of air through the DW, and outdoor air is used as the regeneration air, as illustrated in Figure 8.

\subsection{Config. D: Desiccant-based evaporative cooling system operating in modified ventilation cycle}

Config. D is the modified version of the ventilation cycle. In this cycle, ambient air is used as the regeneration air instead of return air in the ventilation cycle. This configuration is proposed for the situations where building's exhaust air is not located in a convenient location for coprocessing of outdoor air or is not centralized for some applications, see Figure 9.

It is shown that the thermal Coefficient Of Performance (COP) and cooling capacity of the modified ventilation cycle are less than the ventilation cycle; this may be because of the fact that, normally, the ambient air temperature and humidity ratio are higher than the return airside temperature and humidity ratio.

\subsection{Config. E: Desiccant-based evaporative cooling system operating in modified recirculation cycle with pre-cooling}

To enhance the cooling capacity of the explained recirculation cycle, the recirculation cycle was modified. In the modified recirculation cycle, the return air stream as the process air passes through an indirect evaporative cooling unit before entering the DW (Figure 10). The indirect evaporative cooling unit decreases the air temperature and increases the Relative Humidity $(\mathrm{RH})$ of the air. The ambient air is used as the regeneration air in the modified recirculation cycle with pre-cooling.

\subsection{Config. F: Desiccant-based evaporative cooling system operating in ventilation cycle with double series $E \boldsymbol{W}$}

The thermal effectiveness of the rotary EW is expected to have a considerable effect on the performance of the ventilation cycle. However, the maximum recommended effectiveness for the EW is normally $80 \%$. Therefore, to improve the energy wheel effect on the systems, double EW units were proposed. In this configuration, DW leaving air stream passes through a double EW in series before entering the evaporative cooling unit. Figure 11 illustrates the schematic diagram of the double rotary EW.

\section{Simulation process for the desiccant-based configurations in TRNSYS studio}

In order to simulate the configurations in TRNSYS, the equipment in the configurations needs to be defined. As already explained, the standard components are 


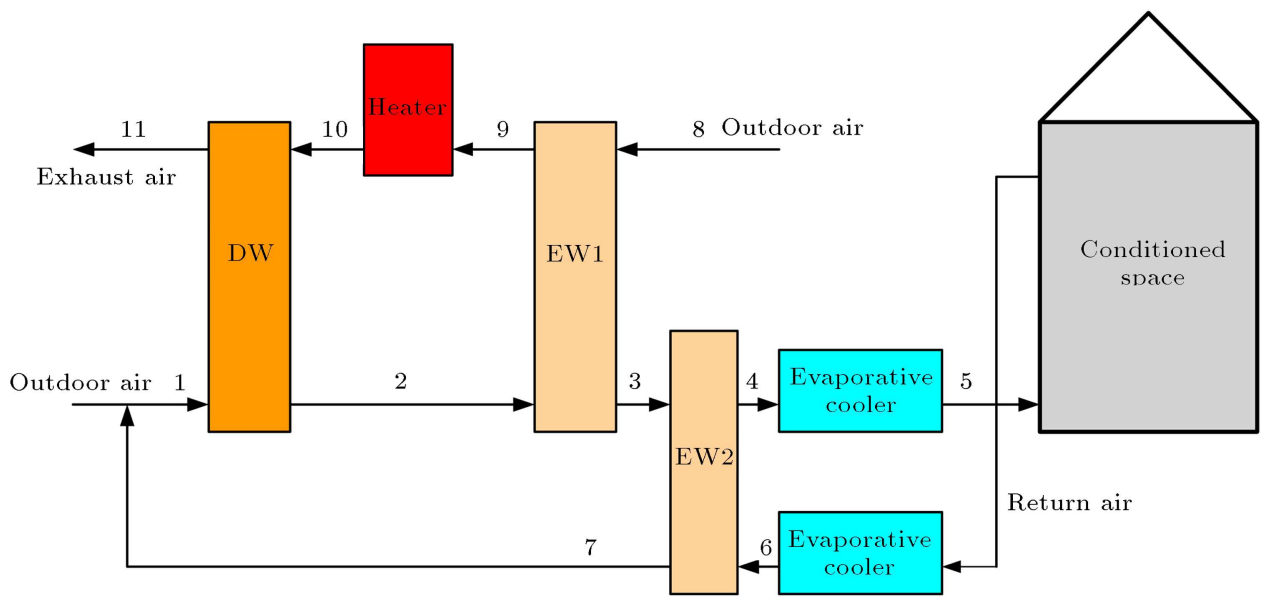

Figure 8. Desiccant-based evaporative cooling system operating in Dunkle cycle [27].

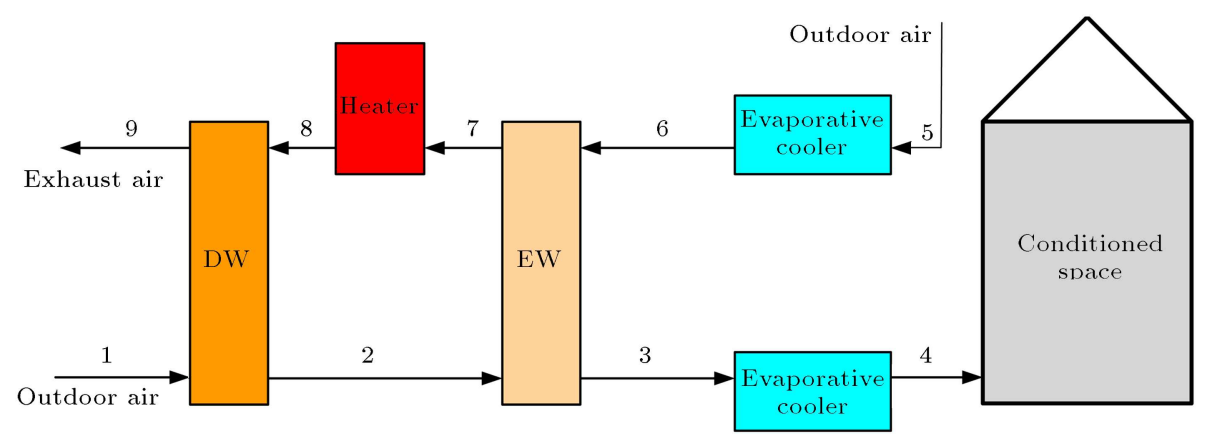

Figure 9. Modified ventilation cycle [28].

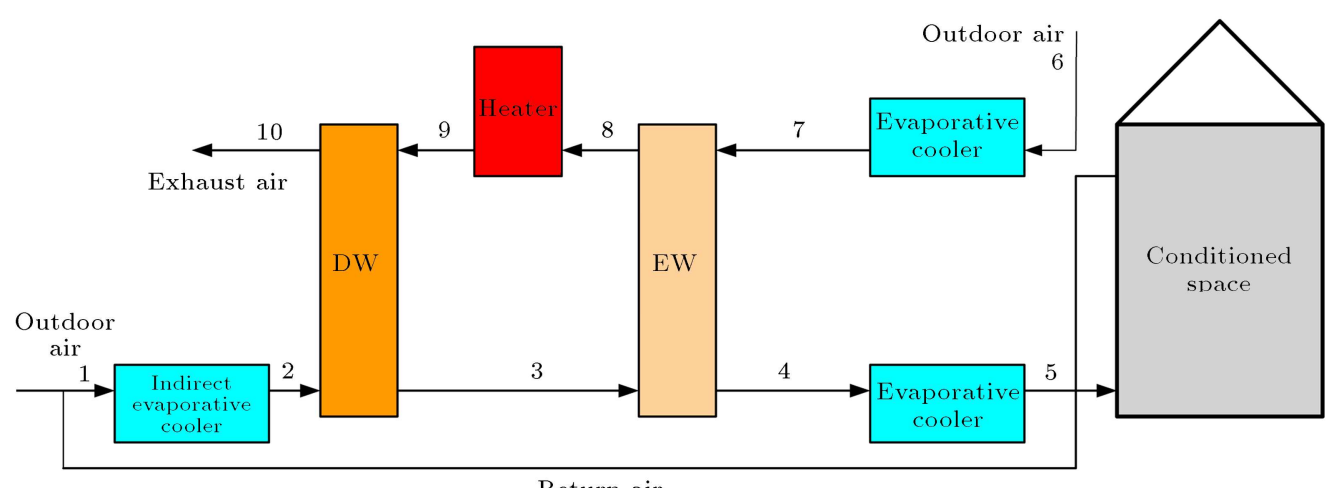

Figure 10. Modified recirculation cycle with pre-cooling [29].

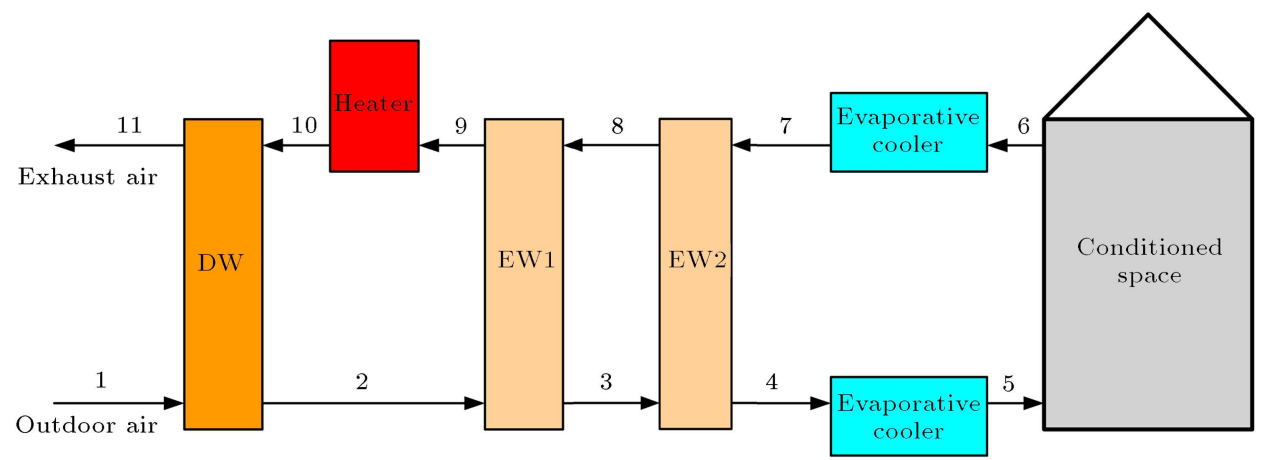

Figure 11. Ventilation cycle with double EW. 
available in the software library and can be used for simulation purposes. However, the non-standard components need to be defined as the new components (user-defined components). To this end, the mathematical performance of the equipment must be derived first. Then, the mathematical performance of the equipment is written as a FORTRAN source code and added into the software library.

\subsection{DW component}

To define the DW as a component in TRNSYS library, the mathematical performance of the considered DW needs to be obtained. In this study, a DW manufactured by Naval Co. [30] was planned to be implemented. In order to provide the regeneration air heating energy by the solar collector panels, the selected DW was considered to operate with $25 \%$ area for reactivation air and $75 \%$ area for the process air. The selected DW contains silica gel as the desiccant material and is designed for regeneration temperatures up to $176^{\circ} \mathrm{C}$. Figure 12 shows the DW specifications.

The performance characteristic curves of the DW were derived by a selection software product provided by the supplier [30]. For this purpose, the Process Air Inlet Temperature (PAIT) was categorized into temperature ranges, namely lower than $10^{\circ} \mathrm{C}, 10$ $15^{\circ} \mathrm{C}, 15-20^{\circ} \mathrm{C}, 20-25^{\circ} \mathrm{C}, 25-30^{\circ} \mathrm{C}, 30-35^{\circ} \mathrm{C}, 35-40^{\circ} \mathrm{C}$, $40-45^{\circ} \mathrm{C}$, and higher than $45^{\circ} \mathrm{C}$. The Process Air Leaving Temperature (PALT), the Process Air Leaving RH (PALRH), the Regeneration Air Leaving Temperature (RALT), and the Regeneration Air Leaving RH (RALRH) software produced data were obtained, and the performance characteristic curves were drawn. Figures 13 and 14 show the performance curves of the DW for the temperature range of $30-35^{\circ} \mathrm{C}$ as the representative. Then, the performance equations of the DW were extracted from the performance characteristic curves written as a FORTRAN source

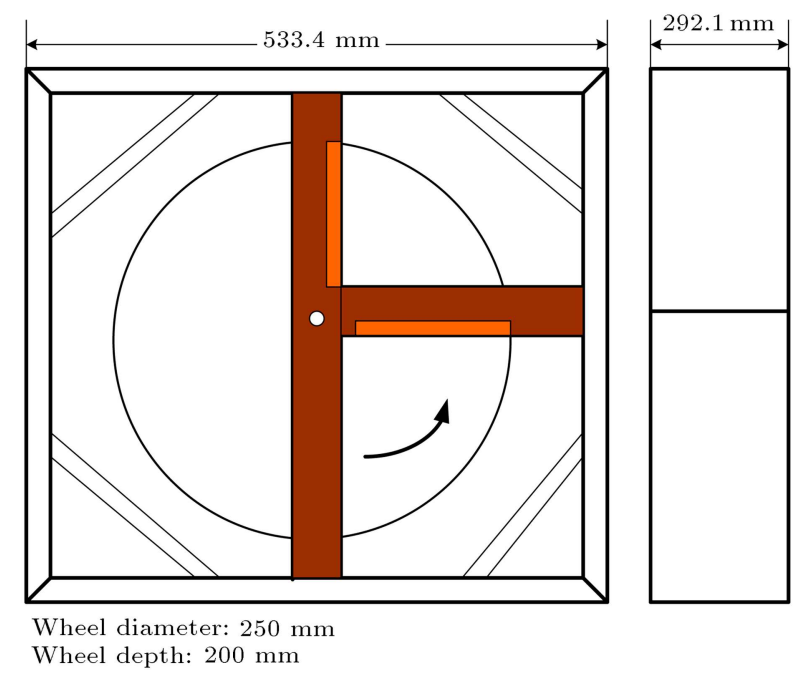

Figure 12. The DW specification.

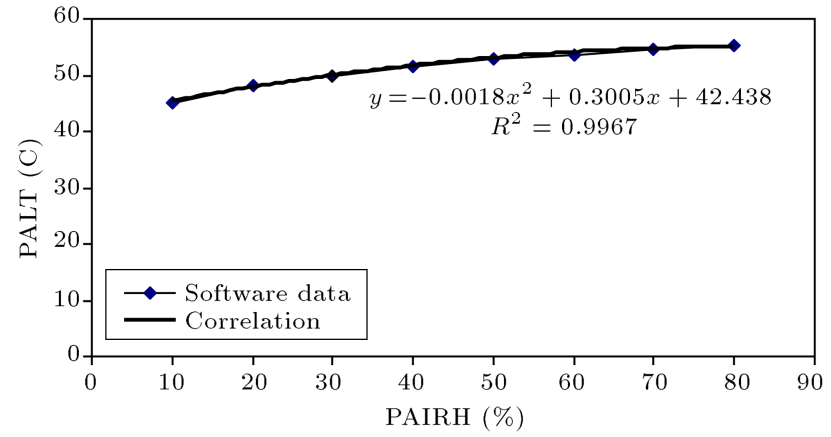

Figure 13. PALT versus PAIRH for inlet temperature range of $30-35^{\circ} \mathrm{C}$.

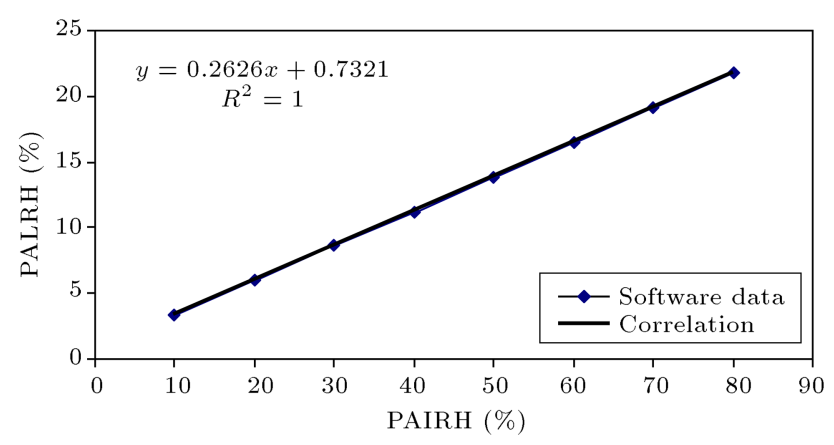

Figure 14. PALRH versus PAIRH for inlet temperature range of $30-35^{\circ} \mathrm{C}$.

code to represent the DW performance mathematically in TRNSYS studio. The performance characteristic equations of the DW are tabulated in Table 2.

\subsection{Energy converting units}

The mathematical modeling of the DW is presented in Subsection 6.1. In this section, the mathematical modelling of the used thermal units, namely direct evaporative cooler, indirect evaporative cooler, rotary $\mathrm{EW}$, and heater, is presented.

The performance of the evaporative coolers is given by the following equation:

$$
\varepsilon=\frac{T_{\text {in }}-T_{\text {out }}}{T_{\text {in }}-T_{w b, \text { in }}} .
$$

In this study, the direct and indirect evaporative coolers were modelled with $90 \%$ and $80 \%$ effectiveness, respectively [31].

The rotary EW was considered as a sensible thermal unit and modelled with $80 \%$ effectiveness [15]. Eq. (2) presents the performance of the rotary EW. The schematic diagram and specification of the EW are illustrated in Figure 15:

$$
\varepsilon=\frac{T_{s, \text { in }}-T_{s, \text { out }}}{T_{s, \text { in }}-T_{r, \text { in }}}
$$

The heater component is a part of the DW, and a $3.61 \mathrm{~kW}$ heater was considered. By considering the heater power as a known parameter, the reactivation 
Table 2. Performance characteristic equations of the DW.

\begin{tabular}{|c|c|c|}
\hline PAIT range & Performance equation & \\
\hline \multirow{4}{*}{$40^{\circ} \mathrm{C}<\operatorname{PAIT}<=45^{\circ} \mathrm{C}$} & $\mathrm{PALT}=0.0039^{*} \mathrm{PAIT}^{*} \mathrm{PAIT}+0.4314^{*} \mathrm{PAIT}+50.72$ & $R^{2}=0.99$ \\
\hline & PALRH $=0.319^{*}$ PAIT +1.25 & $R^{2}=0.99$ \\
\hline & $\mathrm{RALT}=0.0116^{*} \mathrm{PAIT}^{*} \mathrm{PAIT}-1.2923^{*} \mathrm{PAIT}+82.68$ & $R^{2}=0.99$ \\
\hline & $\mathrm{RALRH}=0.0013^{*} \mathrm{PAIT}^{*} \mathrm{PAIT}+0.7929^{*} \mathrm{PAIT}-0.98$ & $R^{2}=0.99$ \\
\hline \multirow{4}{*}{$35^{\circ} \mathrm{C}<\operatorname{PAIT}<=40^{\circ} \mathrm{C}$} & $\mathrm{PALT}=-0.0028^{*} \mathrm{PAIT}^{*} \mathrm{PAIT}+0.3721^{*} \mathrm{PAIT}+46.52$ & $R^{2}=0.99$ \\
\hline & PALRH $=0.286^{*}$ PAIT +1.12 & $R^{2}=0.99$ \\
\hline & RALT $=0.0095^{*}$ PAIT $^{*}$ PAIT $-1.171^{*}$ PAIT +80.94 & $R^{2}=0.99$ \\
\hline & $\mathrm{RALRH}=0.0041^{*} \mathrm{PAIT}^{*} \mathrm{PAIT}+0.6347^{*} \mathrm{PAIT}+0.52$ & $R^{2}=0.99$ \\
\hline \multirow{4}{*}{$30^{\circ} \mathrm{C}<\operatorname{PAIT}<=35^{\circ} \mathrm{C}$} & PALT $=-0.0018^{*} \mathrm{PAIT}^{*} \mathrm{PAIT}+0.3005^{*} \mathrm{PAIT}+42.433$ & $R^{2}=0.99$ \\
\hline & $\mathrm{PALRH}=0.2626^{*} \mathrm{PAIT}+0.7321$ & $R^{2}=1$ \\
\hline & RALT $=0.0054^{*}$ PAIT $^{*}$ PAIT $-0.9007^{*}$ PAIT +77.65 & $R^{2}=0.99$ \\
\hline & $\mathrm{RALRH}=0.0015^{*} \mathrm{PAIT}^{*} \mathrm{PAIT}+0.7276^{*} \mathrm{PAIT}-0.7375$ & $R^{2}=0.99$ \\
\hline \multirow{4}{*}{$25^{\circ} \mathrm{C}<\operatorname{PAIT}<=30^{\circ} \mathrm{C}$} & PALT $=-0.0015^{*}$ PAIT $^{*}$ PAIT $+0.2727^{*}$ PAIT +37.827 & $R^{2}=0.99$ \\
\hline & $\mathrm{PALRH}=0.2335^{*} \mathrm{PAIT}+0.3821$ & $R^{2}=0.99$ \\
\hline & RALT $=0.0045^{*}$ PAIT $^{*}$ PAIT $-0.8243^{*}$ PAIT +76.596 & $R^{2}=0.99$ \\
\hline & RALRH $=0.0035^{*}$ PAIT $^{*}$ PAIT $+0.522^{*}$ PAIT +1.7143 & $R^{2}=0.99$ \\
\hline \multirow{4}{*}{$20^{\circ} \mathrm{C}<\operatorname{PAIT}<=25^{\circ} \mathrm{C}$} & PALT $=-0.0015^{*} \mathrm{PAIT}^{*} \mathrm{PAIT}+0.27^{*} \mathrm{PAIT}+32.739$ & $R^{2}=0.99$ \\
\hline & $\mathrm{PALRH}=0.2018^{*} \mathrm{PAIT}+0.0321$ & $R^{2}=0.99$ \\
\hline & RALT $=0.0044^{*} \mathrm{PAIT}^{*} \mathrm{PAIT}-0.8132^{*} \mathrm{PAIT}+76.741$ & $R^{2}=0.99$ \\
\hline & $\mathrm{RALRH}=0.0033^{*} \mathrm{PAIT}^{*} \mathrm{PAIT}+0.4879^{*} \mathrm{PAIT}+1.4571$ & $R^{2}=0.99$ \\
\hline \multirow{4}{*}{$15^{\circ} \mathrm{C}<\operatorname{PAIT}<=20^{\circ} \mathrm{C}$} & PALT $=-0.0015^{*}$ PAIT $^{*}$ PAIT $+0.2667^{*}$ PAIT +27.595 & $R^{2}=0.99$ \\
\hline & PALRH $=0.0008^{*}$ PAIT $^{*}$ PAIT $+0.0913^{*}$ PAIT +1.0607 & $R^{2}=0.99$ \\
\hline & RALT $=0.0045^{*} \mathrm{PAIT}^{*} \mathrm{PAIT}-0.8077^{*} \mathrm{PAIT}+77.427$ & $R^{2}=0.99$ \\
\hline & $\mathrm{RALRH}=0.002^{*} \mathrm{PAIT}^{*} \mathrm{PAIT}+0.4923^{*} \mathrm{PAIT}+0.8393$ & $R^{2}=0.99$ \\
\hline \multirow{4}{*}{$10^{\circ} \mathrm{C}<\operatorname{PAIT}<=15^{\circ} \mathrm{C}$} & $\mathrm{PALT}=-0.0012^{*} \mathrm{PAIT}^{*} \mathrm{PAIT}+0.2444^{*} \mathrm{PAIT}+22.479$ & $R^{2}=0.99$ \\
\hline & PALRH $=0.0011^{*}$ PAIT $^{*}$ PAIT $+0.0178^{*}$ PAIT +1.9946 & $R^{2}=0.99$ \\
\hline & RALT $=0.0037^{*} \mathrm{PAIT}^{*} \mathrm{PAIT}-0.7313^{*} \mathrm{PAIT}+77.489$ & $R^{2}=0.99$ \\
\hline & $\mathrm{RALRH}=0.0029^{*} \mathrm{PAIT}^{*} \mathrm{PAIT}+0.3465^{*} \mathrm{PAIT}+1.6571$ & $R^{2}=0.99$ \\
\hline \multirow{4}{*}{$\operatorname{PAIT}<=10^{\circ} \mathrm{C}$} & PALT $=-0.0007^{*}$ PAIT $^{*}$ PAIT $+0.1896^{*}$ PAIT +17.932 & $R^{2}=0.99$ \\
\hline & PALRH $=0.0008^{*}$ PAIT $^{*}$ PAIT $-0.0154^{*}$ PAIT +2.7161 & $R^{2}=0.99$ \\
\hline & $\mathrm{RALT}=0.002^{*} \mathrm{PAIT}^{*} \mathrm{PAIT}-0.5587^{*} \mathrm{PAIT}+75.961$ & $R^{2}=0.99$ \\
\hline & RALRH $=0.0035^{*} \mathrm{PAIT}^{*} \mathrm{PAIT}+0.1774^{*} \mathrm{PAIT}+3.2429$ & $R^{2}=0.99$ \\
\hline
\end{tabular}

temperature can be determined by the following equation:

$$
T_{\text {out }}=T_{\text {in }}+\frac{Q}{\dot{m} c_{p}} .
$$

After defining the required components for the config- urations, the components were assembled in TRNSYS studio and the simulations were conducted. Figures 16 and 17 illustrate the TRNSYS simulation layout for Config. A and Config. E, respectively, as the representative of the configurations. Functions of the components in Figures 16 and 17 are described in Table 1. 

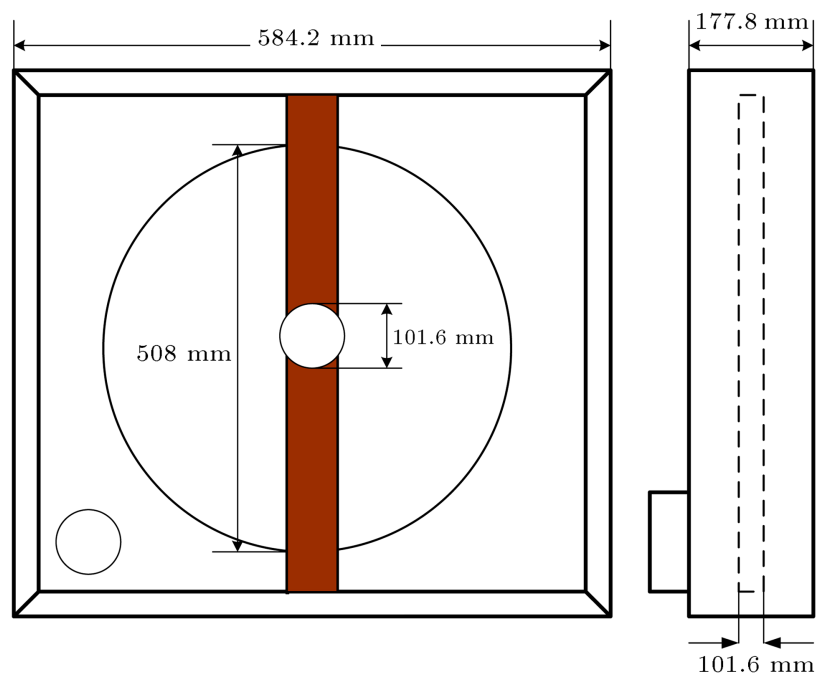

Figure 15. The schematic diagram and specification of the EW.

\section{Array of solar thermal collectors}

One of the considerable advantages of the DCS is the potential of providing the regenerating heat by free resources of energy such as solar energy. With this important characteristic of the DCS, significant amount of energy and cost could be saved. Therefore, the possibility of providing the regeneration process of required heat energy by the solar energy was also explored in this study. For this purpose, an array of solar thermal collectors consist of three different standard solar thermal collectors, namely unglazed, glazed painted absorber, and evacuated tube solar thermal collectors, and they were examined to determine the most appropriate array plant.

Before determining the required array of solar thermal collectors, performance of solar thermal collectors needs to be estimated for the region. Therefore, thermal performance of the solar thermal collectors and operating parameters for the three standard solar panels was considered to define the solar thermal collectors in TRNSYS. The following subsection describes the mathematical performance of the solar thermal collectors.

\subsection{Solar liquid flat-plate thermal collectors}

Thermal performance of the solar thermal collectors normally is given by the following equation as follows:

$$
\eta=\left[F_{R} \tau \alpha-F_{R} U_{L} \frac{\left(t_{i}-t_{a}\right)}{I_{T}}\right] \text {. }
$$

The energy gained by a solar thermal panel is equal to that captured by the fluid minus the indirect and direct heat losses from the collector to the surrounding atmosphere [32]. Therefore, the useful energy delivered by a solar collector can be determined by the following equation [33]:

$$
q_{u}=I_{T} \cdot A_{C} \cdot\left[F_{R} \tau \alpha-F_{R} U_{L} \frac{\left(t_{i}-t_{a}\right)}{I_{T}}\right] .
$$

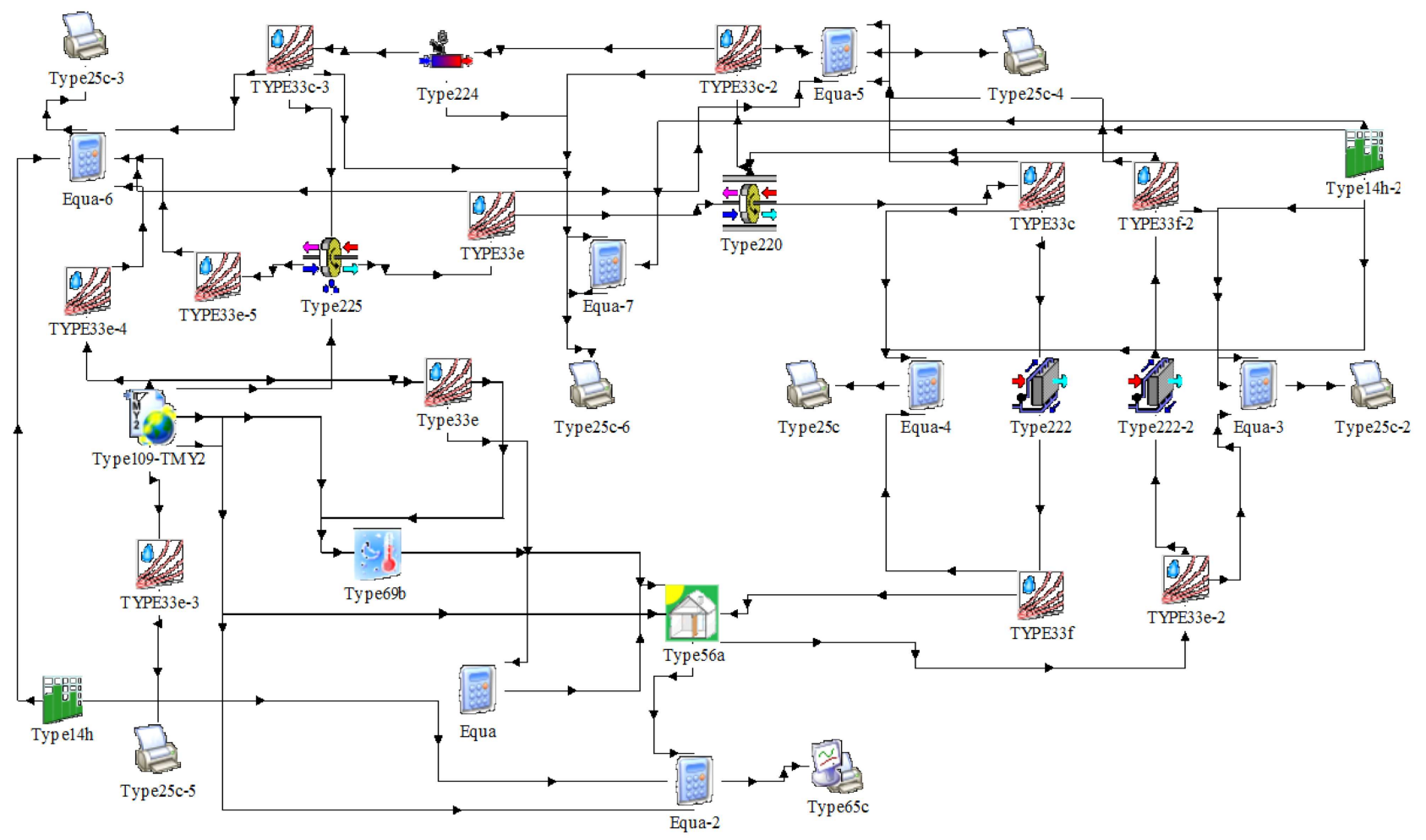

Figure 16. TRNSYS components to simulate responses of the Config. A. 


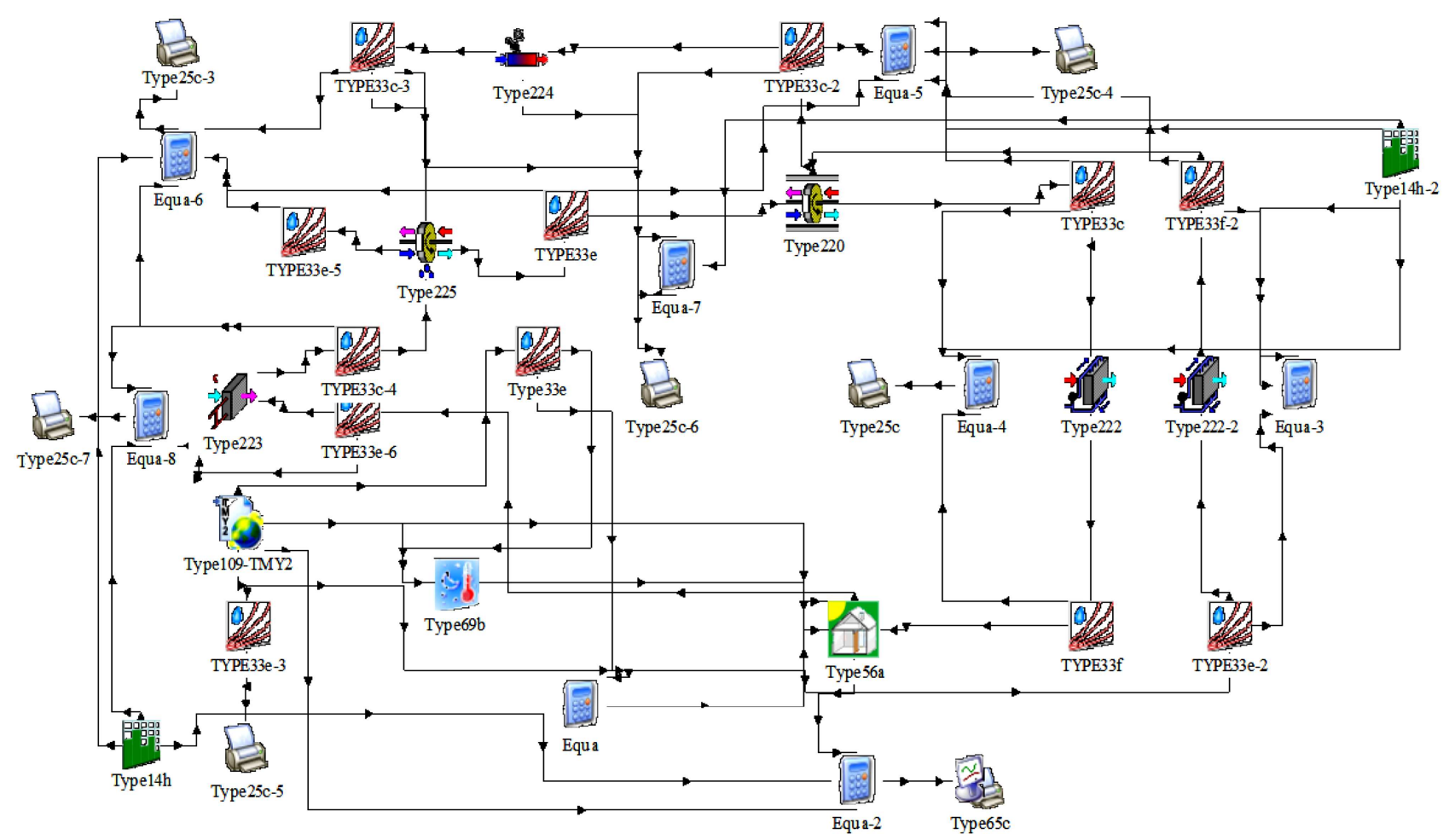

Figure 17. TRNSYS components to simulate responses of the Config. E.

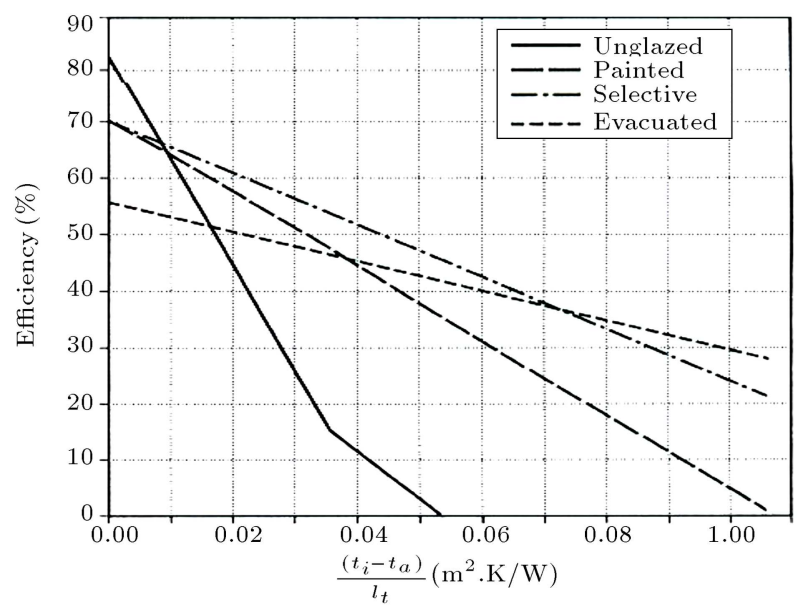

Figure 18. Standard solar thermal collector efficiency curves [32].

Figure 18 shows the efficiency $(\eta)$ curves for the standard liquid flat-plate solar thermal collectors [32]. In Figure 18, the intercept of the curve with the vertical axis gives $F_{R} \tau \alpha$ value and the slope of the line gives $-F_{R} U_{L}$ value.

To derive Eq. (5), it was assumed that the sun is normal to the solar panel; however, this rarely happens. Therefore, it was modified by the incident angle modifier as follows:

$$
K_{\tau \alpha}=\frac{\tau \alpha}{(\tau \alpha)_{n}}=1+b_{0}\left[\frac{1}{\cos \theta}-1\right] .
$$

The solar thermal collector was defined in TRNSYS by writing the mathematical performance characteristic equation in FORTRAN source code and was used in the simulation process. The mean performance parameters of the standard solar thermal collectors are presented in Table 3.

More details on the application of the solar energy as the regeneration heat energy will be discussed later in Section 9.

\subsection{Control strategy of the simulations}

In the preset research, simulations were conducted for the working hours or space occupied hours within a day, which is 8:00 am till 15:00 pm. Therefore, a control strategy was required to be added to the simulation studio. Thus, Type $14 \mathrm{~h}$ as the time controller component was defined based on the space occupied hours.

\section{Simulation results and discussion}

\subsection{Space simulation responses}

To estimate the performance of the explained desiccant-based cooling configurations, thermal performance of the space in terms of indoor air conditions and required cooling energy needs to be determined. As already mentioned, OBCMU was located in the southeast part of the country as a high cooling load demanding area. Figures 19 and 20 show the monthly mean ambient air temperature, $\mathrm{RH}$, and total solar radiation for the region, respectively.

The simulation was conducted for the 12 months 
Table 3. Mean performance parameters for standard types of liquid flat-plate collectors [32,33].

\begin{tabular}{lcc}
\hline Collector type & Vertical intercept & Slope, W/( $\left.\mathbf{m}^{2} . \mathbf{K}\right)$ \\
\hline Unglazed & 0.807 & -18.68 \\
Glazed, painted absorber & 0.701 & -6.53 \\
Evacuated tube & 0.554 & -2.52
\end{tabular}

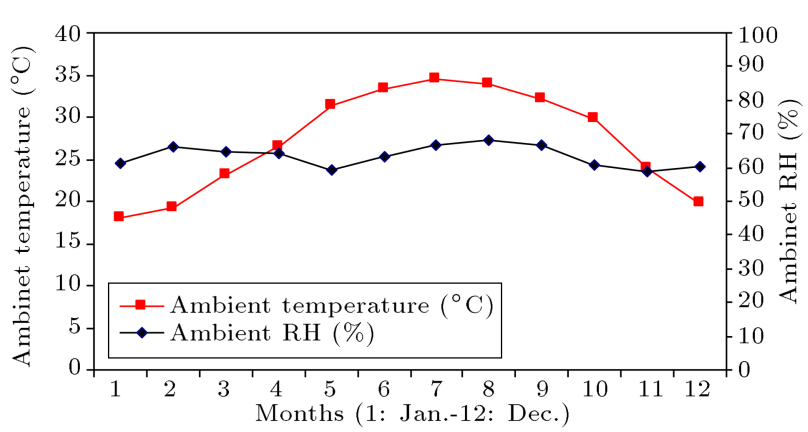

Figure 19. Monthly mean ambient air temperature and RH.

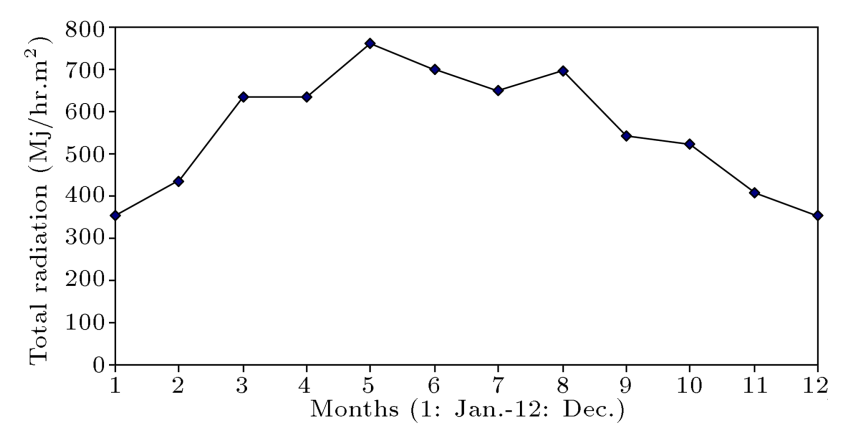

Figure 20. Monthly mean total solar radiation.

of the year, and the mean values are tabulated in Table 4. Two mean values as means $24 \mathrm{~h}$ and $8 \mathrm{~h}$ were tabulated. In this research, mean $8 \mathrm{~h}$ values as the space occupied hours were considered as the reference for the simulations and analyses.

Figure 21 illustrates the existing space of hourly simulation responses for typical May as the represen-

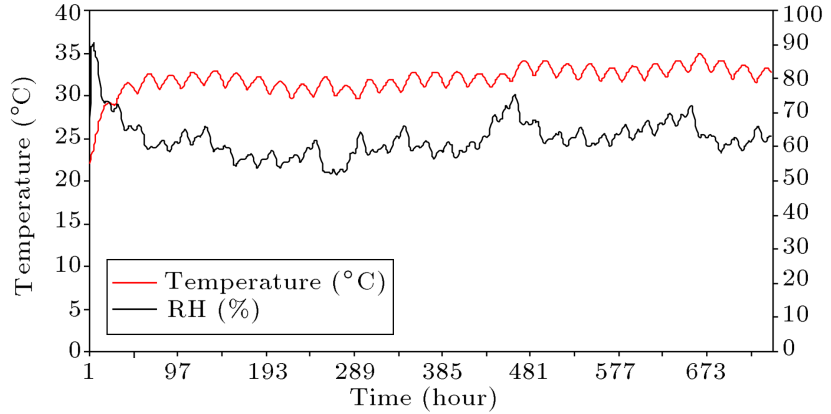

Figure 21. Hourly simulation responses of the existing space (space without DCS) for typical May.

tative. Based on Figure 21, the mean indoor air temperature and $\mathrm{RH}$ are $31.9^{\circ} \mathrm{C}$ and $62.4 \%$, which are out of the standard recommendations. The fieldwork measurements showed less than $10 \%$ deviation with the simulation results.

Based on the ASHRAE recommendations [34], space design temperature and $\mathrm{RH}$ are recommended to be within $23-26^{\circ} \mathrm{C}$ and $50-60 \%$, respectively. Therefore, the months with indoor air conditions out of the standard recommendations were considered for further simulations. According to Table 4, these months are: March, April, May, June, July, August, September, October, and November.

\subsection{Simulation results for the DCS configurations}

In this section the simulation results for the established indoor air conditions and energy analysis are being discussed. The established indoor air conditions are

Table 4. Mean indoor air temperature and existing RH space (space without the DCS).

\begin{tabular}{ccccc}
\hline \multirow{2}{*}{ Month } & \multicolumn{2}{c}{ Mean $(\mathbf{2 4} \mathbf{~ h})$} & \multicolumn{2}{c}{ Mean $(\mathbf{8} \mathbf{~ h})$} \\
\cline { 2 - 5 } & I.T. $\left({ }^{\circ} \mathbf{C}\right)$ & I.RH (\%) & I.T. $\left({ }^{\circ} \mathbf{C}\right)$ & I.RH (\%) \\
\hline Jan. & 24.6 & 50.5 & 24.5 & 51.2 \\
Feb. & 25.5 & 53.9 & 25.4 & 54.6 \\
Mar. & $\mathbf{2 7 . 8}$ & 56.5 & $\mathbf{2 7 . 7}$ & 57.3 \\
Apr. & $\mathbf{2 9 . 4}$ & 60.4 & $\mathbf{2 9 . 3}$ & 61.5 \\
May. & $\mathbf{3 1 . 9}$ & 62.4 & $\mathbf{3 1 . 8}$ & 63.4 \\
Jun. & $\mathbf{3 2 . 9}$ & 69.9 & $\mathbf{3 2 . 8}$ & 71.0 \\
Jul. & $\mathbf{3 3 . 3}$ & 76.1 & $\mathbf{3 3 . 2}$ & 77.2 \\
Aug. & $\mathbf{3 3 . 2}$ & 76.0 & $\mathbf{3 3 . 1}$ & 77.1 \\
Sep. & $\mathbf{3 1 . 9}$ & 72.7 & $\mathbf{3 1 . 9}$ & 73.8 \\
Oct. & $\mathbf{3 0 . 6}$ & 63.5 & $\mathbf{3 0 . 6}$ & 64.5 \\
Nov. & $\mathbf{2 7 . 6}$ & 54.7 & $\mathbf{2 7 . 6}$ & 55.3 \\
Dec. & 25.4 & 51.2 & 25.3 & 52.0 \\
\hline
\end{tabular}


discussed in Subsection 8.2.1 and energy analysis are provided in Subsection 8.2.2.

\subsubsection{Established indoor air conditions}

Figure 22 shows the provided indoor air conditions by Config. A as the ventilation cycle. The simulation outcomes for eight working hours of a day (8:00 am till 15:00 pm) were presented for typical April, as the representative of the months simulated. As Figure 22 illustrates, Config. A is capable of keeping indoor air at $23.7^{\circ} \mathrm{C}$ and $54.5 \%$ for typical April. For more convenience, the simulation values are tabulated in Table 5. Based on the tabulated values in Table 5, Config. A has the potential to keep March, April, October, and November within the standard recommendations; however, four months, namely, May, June, July, August, and September, still require extra cooling energy to be conditioned.

Config. B as the recirculation cycle was simulated for the considered nine months, and the results are also tabulated in Table 5. According to the simulation results, Config. B is capable of keeping four months,

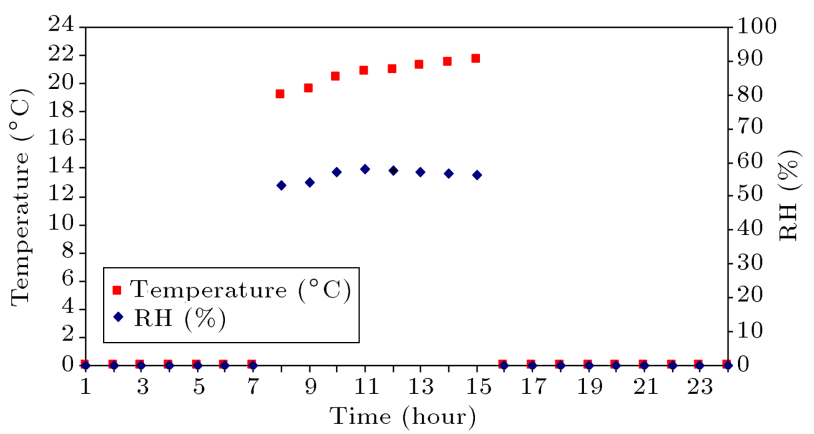

Figure 22. Hourly simulated indoor air conditions within eight working hours of a day (8:00 am till 15:00 pm) for typical April by Config. A. namely March, April, October, and November, within the standard recommendations; the rest of the months still require extra cooling energy to be conditioned. Figure 23 illustrates the provided hourly indoor air conditions by Config. B for October.

Based on the simulated mean values for Config. $\mathrm{C}$, the Dunkle cycle is also capable of keeping March, April, October, and November within the desired conditions, and indoor air conditions for the rest of the months are still out of the recommendations.

Config. D performance is also tabulated in Table 5. It was indicated that Config. D is capable of keeping three out of nine considered months within the desired conditions. Moreover, Config. E as the modified recirculation cycle has the capability to establish six out of nine considered months within the standard recommendations; the three months, namely June, July, and August, are also marginally inside the thermal comfort zone. Config. E has the potential to maintain the indoor air at $21.2^{\circ} \mathrm{C}, 22.8^{\circ} \mathrm{C}, 25^{\circ} \mathrm{C}, 25.4^{\circ} \mathrm{C}, 24^{\circ} \mathrm{C}$, and $21.1^{\circ} \mathrm{C}$ in March, April, May, September, October, and November, respectively. Furthermore, the simula-

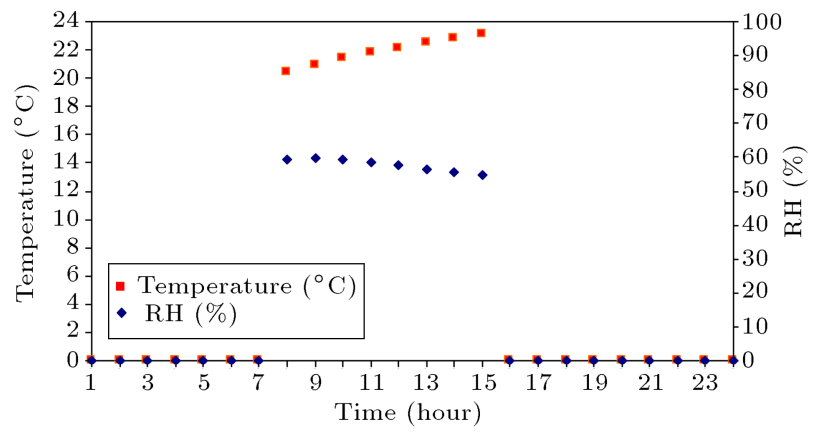

Figure 23. Hourly simulated indoor air conditions within eight working hours of a day (8:00 am till 15:00 pm) for typical October by Config. B.

Table 5. Mean indoor air conditions established by the configurations.

\begin{tabular}{|c|c|c|c|c|c|c|c|c|c|c|c|c|}
\hline \multirow[b]{2}{*}{ Months } & \multicolumn{2}{|c|}{ Config. A } & \multicolumn{2}{|c|}{ Config. B } & \multicolumn{2}{|c|}{ Config. C } & \multicolumn{2}{|c|}{ Config. D } & \multicolumn{2}{|c|}{ Config. E } & \multicolumn{2}{|c|}{ Config. F } \\
\hline & $\begin{array}{l}\text { I.T. } \\
\left({ }^{\circ} \mathrm{C}\right)\end{array}$ & $\begin{array}{c}\text { I.RH } \\
(\%)\end{array}$ & $\begin{array}{l}\text { I.T. } \\
\left({ }^{\circ} \mathrm{C}\right)\end{array}$ & $\begin{array}{c}\text { I.RH } \\
(\%)\end{array}$ & $\begin{array}{l}\text { I.T. } \\
\left({ }^{\circ} \mathrm{C}\right)\end{array}$ & $\begin{array}{c}\text { I.RH } \\
(\%)\end{array}$ & $\begin{array}{l}\text { I.T. } \\
\left({ }^{\circ} \mathrm{C}\right)\end{array}$ & $\begin{array}{c}\text { I.RH } \\
(\%)\end{array}$ & $\begin{array}{l}\text { I.T. } \\
\left({ }^{\circ} \mathrm{C}\right)\end{array}$ & $\begin{array}{c}\text { I.RH } \\
(\%)\end{array}$ & $\begin{array}{l}\text { I.T. } \\
\left({ }^{\circ} \mathrm{C}\right)\end{array}$ & $\begin{array}{c}\text { I.RH } \\
(\%)\end{array}$ \\
\hline \multicolumn{13}{|l|}{ Jan. } \\
\hline \multicolumn{13}{|l|}{ Feb. } \\
\hline Mar. & 21.7 & 50.5 & 21.8 & 49.4 & 21.2 & 49.1 & 22.2 & 51.9 & 21.2 & 46.7 & 21.2 & 49.2 \\
\hline Apr. & 23.7 & 54.5 & 23.5 & 51.0 & 23.2 & 52.8 & 24.3 & 56.0 & 22.8 & 48.2 & 23.3 & 53.2 \\
\hline May. & 26.9 & 59.2 & 26.1 & 52.2 & 26.5 & 57.4 & 27.5 & 60.4 & 25.0 & 48.0 & 26.5 & 58.0 \\
\hline Jun. & 28.3 & 63.3 & 27.2 & 54.7 & 27.9 & 61.7 & 28.9 & 64.5 & 26.2 & 50.8 & 27.9 & 62.2 \\
\hline Jul. & 28.9 & 65.5 & 27.7 & 56.6 & 28.5 & 64.3 & 29.5 & 66.7 & 26.8 & 53.3 & 28.5 & 64.4 \\
\hline Aug. & 28.7 & 64.6 & 27.6 & 56.6 & 28.3 & 63.3 & 29.3 & 65.9 & 26.8 & 53.3 & 28.2 & 63.5 \\
\hline Sep. & 27.2 & 62.7 & 26.5 & 56.2 & 26.8 & 61.2 & 27.8 & 64.1 & 25.4 & 51.9 & 26.8 & 61.6 \\
\hline Oct. & 25.7 & 58.7 & 24.9 & 52.3 & 25.2 & 57.0 & 26.2 & 60.1 & 24.0 & 48.8 & 25.2 & 57.5 \\
\hline $\begin{array}{l}\text { Nov. } \\
\text { Dec. }\end{array}$ & 21.9 & 51.5 & 21.7 & 49 & 21.4 & 49.8 & 22.4 & 52.9 & 21.1 & 46.3 & 21.4 & 50.1 \\
\hline
\end{tabular}


tion results indicated that Config. F could establish the indoor air conditions within the thermal comfort zone in four out of nine months and five out of nine months still require extra cooling load to be treated.

By comparison of the configurations performances, it is clear that Config. E as the pre-cooled recirculation cycle is the superior configuration in terms of the provided indoor air conditions and recommended to be incorporated into the space.

\subsubsection{Energy analysis}

In this section, the performances of the desiccant-based configurations are discussed in terms of the energy point of view. To this end, the required cooling energies for the existing space (space without the DCS) and space with the desiccant-based configurations were determined and compared.

The existing space's required cooling load was estimated by the comparison between the simulated monthly indoor air conditions and design indoor air conditions. The heat required to be removed from the space was estimated by the difference between the enthalpy of the simulated values $\left(h_{i . a}\right)$ and the desired value $\left(h_{\text {d.a }}\right)$. Psychrometric chart was used for this purpose. $\Delta h_{e . s}=h_{i . a}-h_{d . a}$ value was used as a measure for cooling energy estimation purposes in this research.

The enthalpy differences between the simulated indoor air conditions and design air condition for the existing space are tabulated in Table 6. According to Table 6, the highest cooling energy is required in July with the highest indoor air temperature.

Values in Table 6 are used as the reference values to estimate the effect of desiccant-based cooling configurations on the space. The energy performances of the examined configurations were analyzed based on the extra-required cooling load to keep the indoor air within the desired conditions. This time again, the enthalpy difference between the indoor air and design air for the configurations $\left(\Delta h_{\text {d.c.s }}\right)$ was considered as a measure to estimate the required extra cooling energy by the space. In addition, $\Delta h_{\text {Config }}=\Delta h_{\text {d.c.s }}-$ $\Delta h_{\text {e.s }}$ value was evaluated to estimate the cooling load reduction by the space with the added desiccantbased configurations. The monthly performance of the configurations was estimated, and they are tabulated in Table 7 .

As tabulated in Table 7, Config. E as the modified recirculation cycle with pre-cooling has the capability to provide the indoor air within the standard recommendations without extra cooling energy requirements. Therefore, Config. E as the appropriate configuration was recommended to be implemented for the office buildings in the region.

Configurations COP value was also evaluated to determine the configurations' performance from the energy point of view. COP value is defined as the amount of useful cooling provided to the space and the heat used in the desiccant regenerating process as follows:

$$
\mathrm{COP}=\frac{Q_{\text {zone }}}{Q_{\text {regen }}},
$$

where:

$$
Q_{\text {zone }}=\dot{m}_{\text {supply }}\left(h_{\text {zone }}-h_{\text {supply }}\right) \text {. }
$$

Configurations COP value was calculated for typical July as the representative of the months studied. As tabulated in Table 8, Config. E shows the best performance in terms of energy point of view with the highest value of 0.8 followed by Config. B with 0.71. Config. E monthly value is also investigated and illustrated in Figure 24. According to this figure, Config. E's best performance occurs in July and August with 0.8 value followed by June with 0.78 .

\section{Array of the solar thermal collectors simulation results}

One of the interesting characteristics of the DCS is the possibility of providing the desiccant regeneration heat

Table 6. Existing space required for cooling energy.

\begin{tabular}{cccc}
\hline Months & $\begin{array}{c}\boldsymbol{h}_{\text {i.a }} \\
(\mathbf{k J} / \mathbf{k g})\end{array}$ & $\begin{array}{c}\boldsymbol{h}_{\text {d.a }} \\
(\mathbf{k J} / \mathbf{k g})\end{array}$ & $\begin{array}{c}\Delta \boldsymbol{h}_{\text {e.s }}=\boldsymbol{h}_{\text {i.a }}-\boldsymbol{h}_{\boldsymbol{d} . \boldsymbol{a}} \\
(\mathbf{k J} \mathbf{k g})\end{array}$ \\
\hline Jan. & & & \\
Feb. & & & \\
Mar. & 61.9 & 58.4 & 3.5 \\
Apr. & 69.8 & 58.4 & 11.4 \\
May. & 80.3 & 58.4 & 21.9 \\
Jun. & 90.6 & 58.4 & 32.2 \\
Jul. & 97.7 & 58.4 & 39.3 \\
Aug. & 97.1 & 58.4 & 38.7 \\
Sep. & 88.9 & 58.4 & 30.5 \\
Oct. & 76.5 & 58.4 & 18.1 \\
Nov. & 60.4 & 58.4 & 2 \\
Dec. & & & \\
\hline
\end{tabular}


Table 7. Energy performance of the configurations compared with the existing space (space without the DCS).

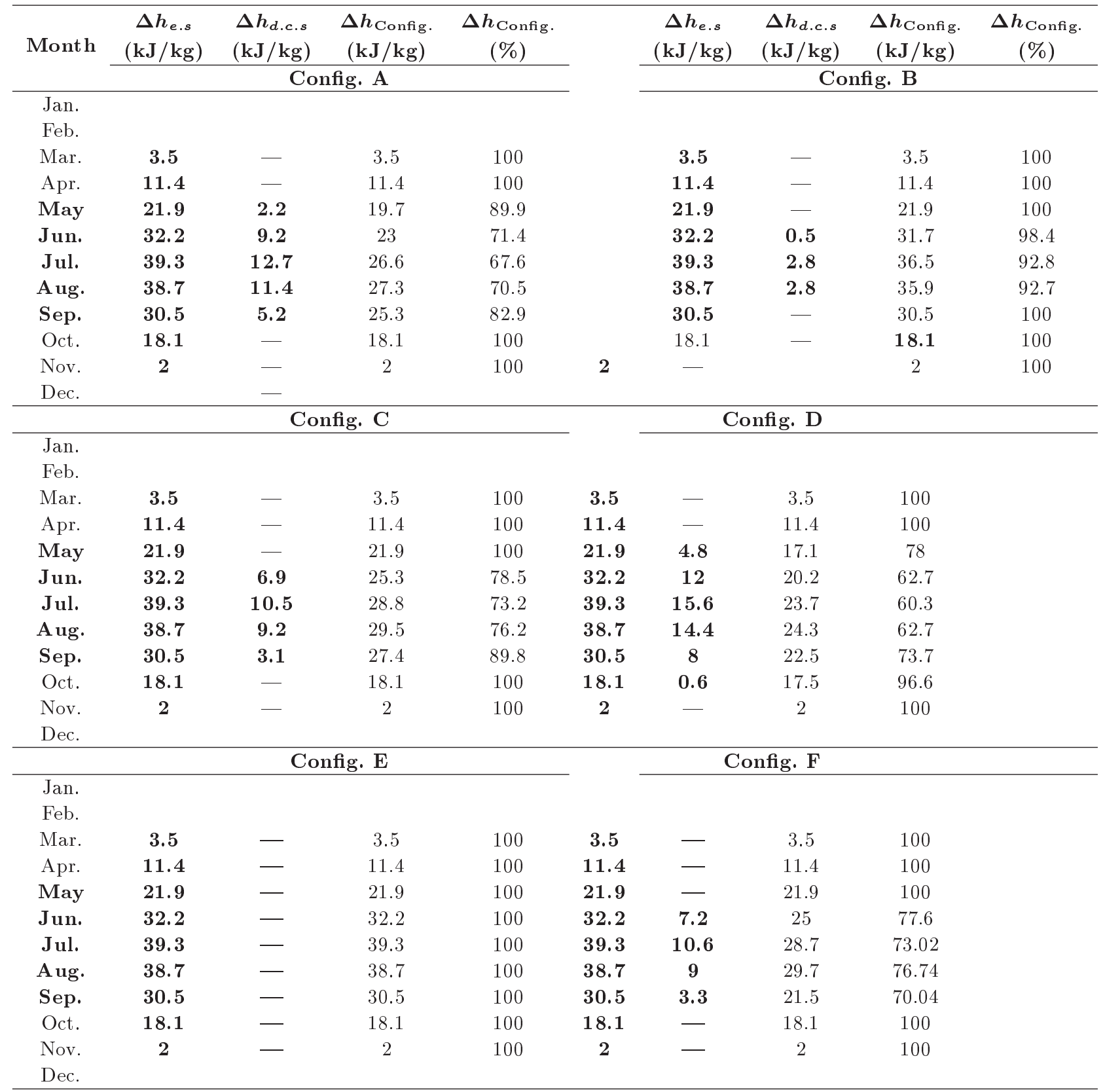

Table 8. COP value of the configurations for typical July.

\begin{tabular}{lccc}
\hline & $\boldsymbol{h}_{\text {supply }}$ & $\boldsymbol{h}_{\text {zone }}$ & $\mathbf{C O P}$ \\
\hline Config. A & 57.6 & 71.1 & 0.52 \\
Config. B & 43 & 61.5 & 0.71 \\
Config. C & 54.1 & 68.9 & 0.57 \\
Config. D & 62.5 & 74 & 0.44 \\
Config. E & 36.2 & 56.9 & 0.80 \\
Config. F & 54.3 & 69 & 0.57 \\
\hline
\end{tabular}

energy by the renewable resources of energy such as solar energy (see Figure 25).

In this study, the feasibility of benefiting from an array of solar thermal collectors to provide the regen- eration heat was investigated. To this end, thermal performance of a single solar panel was evaluated to be used as a selection measure for the array of solar thermal collectors in the region. In addition, to determine the most proper array plant, three standard solar thermal collectors, namely unglazed, glazed painted absorber, and evacuated tube, were examined. The estimation was conducted based on the performance for November as the month with the lowest amount of solar radiation.

According to the simulation results, a single solar thermal collector has the potential to deliver 0.48 $\mathrm{kW}, 0.41 \mathrm{~kW}$, and $0.32 \mathrm{~kW}$ amount of energy for unglazed, glazed painted absorber, and evacuated tube, 


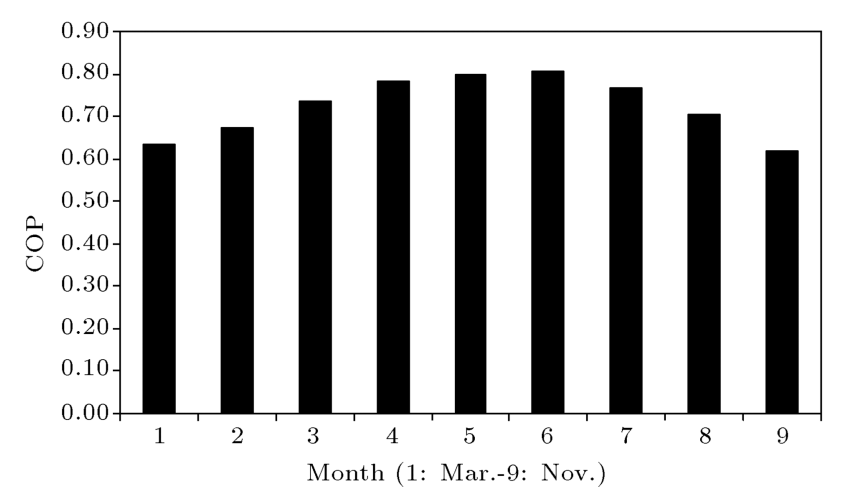

Figure 24. Mean monthly COP value for the Config. E.

respectively. In addition, an array of solar collectors is required to deliver a mean value of $3.61 \mathrm{~kW}$ energy to meet the desiccant regeneration heat. Therefore, an array of solar thermal collectors with the standard unglazed solar collectors is superior in terms of performance and was recommended. By considering the above, three array plants were examined as below:

- Array Plant A: One row of two unglazed solar collector panels with aperture area of $4 \mathrm{~m}^{2}$;

- Array Plant B: Two rows of two unglazed solar collector panels with aperture area of $4 \mathrm{~m}^{2}$;

- Array Plant C: Two rows of four unglazed solar collector panels with aperture area of $4 \mathrm{~m}^{2}$.

Figure 26 shows the simulation layout for the array of solar thermal collectors, and Plant $\mathrm{C}$ as the representative of the arrays was examined. The proposed plants were examined for the November as the month of the lowest amount of solar radiation.
The simulation results showed that Plants A, B, and $\mathrm{C}$ have the capability to deliver mean values of $0.96 \mathrm{~kW}, 1.9 \mathrm{~kW}$, and $3.91 \mathrm{~kW}$ heat energy, respectively. Therefore, it is clear that Plant $\mathrm{C}$ is capable of meeting the regeneration heat requirements and is recommended for the system.

\section{Conclusions}

In the present research study, the application of SDCS to the office buildings in hot regions of Iran was explored. To this end, an office building located in southeast region of the country was considered as the case study. The capability of providing the space with required cooling energy by the SDCS was investigated. The existing space and space integrated with the recommended DCS were studied for a whole year of operation. TRNSYS software was used for this purpose, and the TMY weather data were used as the input file for the program. Six different desiccant-based cooling system configurations were examined in terms of the provided indoor air conditions and energy performance to determine the most appropriate configuration for the space. According to the simulation values, Config. E is the modified recirculation cycle with the desired pre-cooling established indoor air conditions for the simulated months. In addition, the configurations' energy performance was also estimated. The study revealed that Config. $\mathrm{E}$ is the superior configuration in terms of COP value, and it is recommended for the building to be incorporated. Furthermore, the capability of providing the regeneration heat by the free solar energy was also explored. Three standard solar thermal panels, namely unglazed, glazed painted,

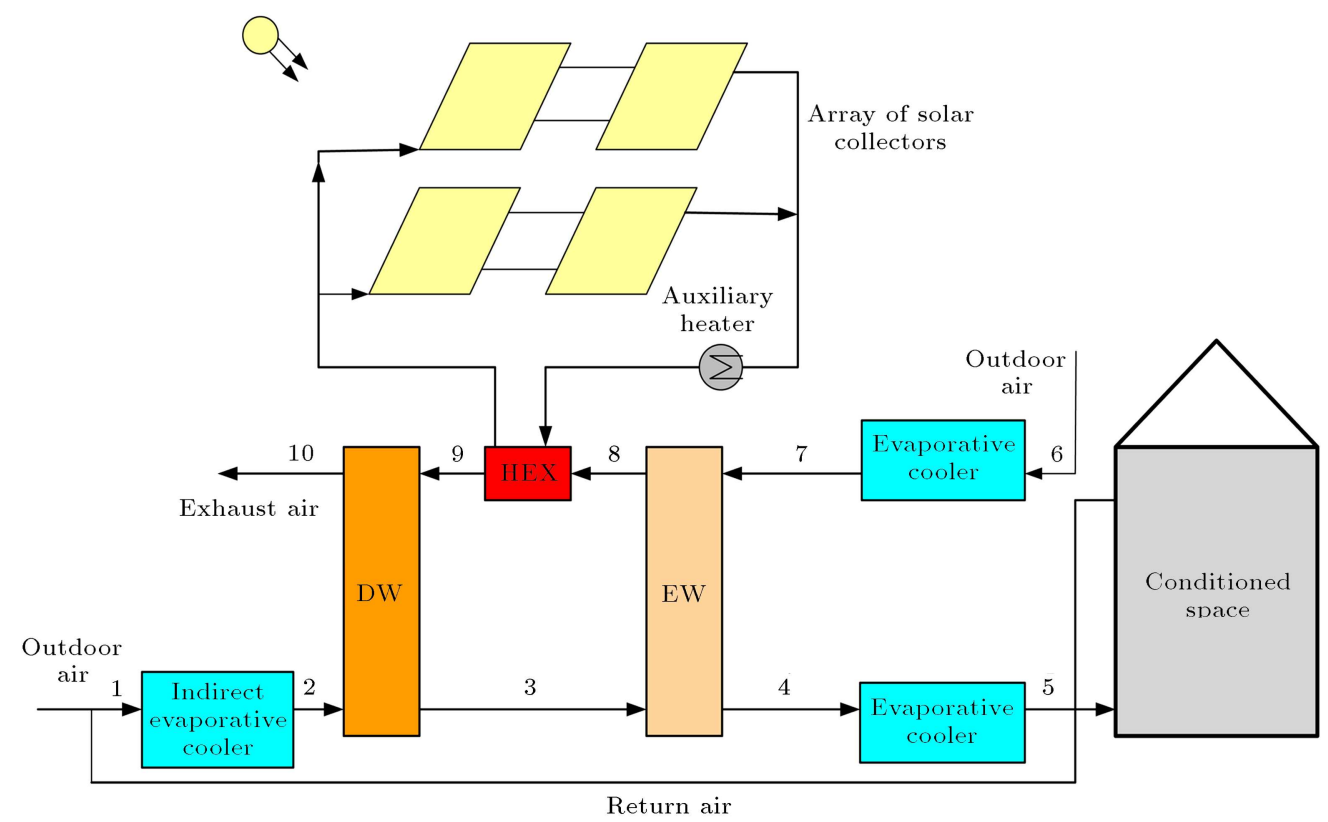

Figure 25. Schematic diagram of the SDCS operating on pre-cooled recirculation cycle. 


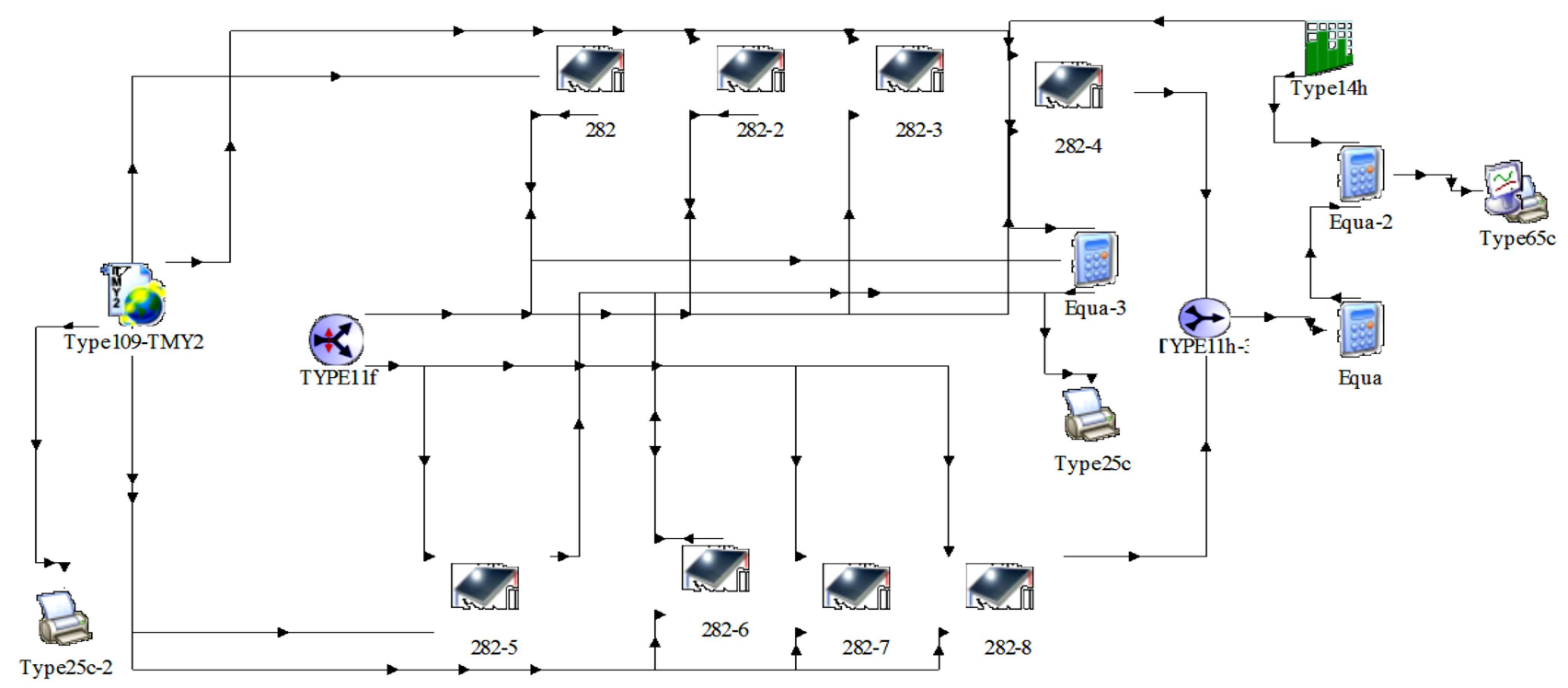

Figure 26. Simulation layout for the array of solar thermal collectors: Plant C.

and evacuated tubes, were examined for this purpose. According to the simulation results, an array of eight panels of unglazed solar thermal collectors with 4 aperture area is capable of providing the process of regeneration heat requirements.

\section{Acknowledgments}

The author would like to thank Chabahar Maritime University (CMU), Iran for its financial support to conduct the present research.

\section{Nomenclature}

$\begin{array}{ll}A_{C} & \text { Total aperture collector area }\left(\mathrm{m}^{2}\right) \\ c_{p} & \text { Specific heat of air }(\mathrm{J} / \mathrm{kgK}) \\ F_{R} & \text { Collector heat removal efficiency factor } \\ I_{T} & \text { Irradiance, total (direct plus diffuse) } \\ & \text { solar energy incident }\left(\mathrm{W} / \mathrm{m}^{2}\right) \\ K_{\tau \alpha} & \text { Incident angle modifier } \\ \dot{m} & \text { Mass flow rate }(\mathrm{kg} / \mathrm{s}) \\ q_{u} & \text { Useful energy delivered by collector } \\ Q & (\text { W) } \\ t_{a} & \text { Heat (kW) } \\ T & \text { Atmospheric temperature }\left({ }^{\circ} \mathrm{C}\right) \\ U_{L} & \text { Temperature }\left({ }^{\circ} \mathrm{C}\right) \\ t_{i} & \text { Overall heat loss coefficient } \\ & \left(\mathrm{W} . / \mathrm{m}^{2} \mathrm{~K}^{-1}\right) \\ & \text { Temperature of fluid entering collector } \\ & \left({ }^{\circ} \mathrm{C}\right)\end{array}$

\section{Greek symbols}

$\varepsilon \quad$ Effectiveness
$\theta \quad$ Incident angle
$\tau \quad$ Transmittance
$\alpha \quad$ Absorptance

\section{Subscripts}

$\begin{array}{ll}s, \text { out } & \text { Supply out } \\ r, \text { in } & \text { Return in } \\ w b & \text { Wet bulb temperature }\left({ }^{\circ} \mathrm{C}\right) \\ \text { e.s. } & \text { Existing space }\end{array}$

\section{Abbreviations}

ASHRAE American Society of Heating, Refrigerating and Air Conditioning Engineers

COP Coefficient of Performance

DCS Desiccant Cooling System

DW Desiccant Wheel

EW Energy Wheel

HVAC Heating, Ventilating, and Air Conditioning systems

I.T Indoor Temperature $\left({ }^{\circ} \mathrm{C}\right)$

I.RH Indoor Relative Humidity (\%)

OBCMU Office Building in Chabahar Maritime University

PAIT Process Air Inlet Temperature $\left({ }^{\circ} \mathrm{C}\right)$

PALT Process Air Leaving Temperature $\left({ }^{\circ} \mathrm{C}\right)$

PALRH Process Air Leaving Relative Humidity $(\%)$

RALT Regeneration Air Leaving Temperature $\left({ }^{\circ} \mathrm{C}\right)$

RALRH Regeneration Air Leaving Relative Humidity (\%) 
$\mathrm{RH}$

$\begin{array}{ll}\text { SDCS } & \begin{array}{l}\text { Solar assisted Desiccant Cooling } \\ \text { System }\end{array}\end{array}$

Relative Humidity (\%)

TMY Typical Meteorological Year

TRNSYS Transient system simulation software

\section{References}

1. "Renewable energy in Islamic republic of Iran", Iran Ministry of Energy, presented in Renewable Energy Conference, Japan (2006).

2. Fadai, D., Esfandabadi, Z.S. and Abbasi, A. "Analyzing the causes of non-development of renewable energyrelated industries in Iran", Renew. Sust. Energ. Rev., 15, pp. 2690-2695 (2011).

3. Hydrocarbon Balance 2008, Iran Institute for International Energy Studies (IIES) (2010).

4. Energy Balance, 2003, Energy Planning Office, Iranian Ministry of Energy (2003).

5. Renewable Energy in Iran, Energy Statistical Review of Iran (2002).

6. Renewable Energy Sources, Islamic Republic of Iran: Iranian Atomic Energy Agency (IAEA) (2010).

7. Li, H., Dai, Y.J., Köhler, M. and Wang, R.Z. "Simulation and parameter analysis of a two-stage desiccant cooing/heating system driven by solar air collectors", Energ. Convers. Manage., 67, pp. 309-317 (2013).

8. Mavroudaki, P., Beggs, C.B., Sleigh, P.A. and Halliday, S.P. "The potential for solar powered single-stage desiccant cooling in southern Europe", Appl. Therm. Eng., 22, pp. 1129-1140 (2002).

9. Joudi Khalid, A. and Dhaidan Nabeel, S. "Application of solar assisted heating and desiccant cooling systems for a domestic building", Energ. Convers. Manage., 42, pp. 995-1022 (2001).

10. Khalid, A., Mahmood, M., Asif, M. and Muneer, T. "Solar assisted, pre-cooled hybrid desiccant cooling system for Pakistan", Renew. Energ., 34, pp. 151-175 (2009).

11. Bourdoukan, P., Wurtz, E. and Joubert, P. "Experimental investigation of a solar desiccant cooling installation", Sol. Energy, 83, pp. 2059-2073 (2009).

12. Ma, Y. and Guan, L. "Performance analysis of solar desiccant-evaporative cooling for a commercial building under different Australian climates", Procedia Eng., 121, pp. 528-535 (2015).

13. Enteria, N., Yoshino, H., Mochida, A., Satake, A., Yoshie, R., Takaki, R., Yonekura, H., Mitamura, T. and Tanaka, Y. "Performance of solar-desiccant cooling system with silica-gel $\left(\mathrm{SiO}_{2}\right)$ and titanium dioxide $\left(\mathrm{TiO}_{2}\right)$ desiccant wheel applied in East Asian climates", Sol. Energy, 86, pp., 1261-1279 (2012).

14. Fong, K.F., Chow, T.T., Lee, C.K., Lin, Z. and Chan, L.S. "Advancement of solar desiccant cooling system for building use in subtropical Hong Kong", Energ. Buildings, 42, pp. 2386-2399 (2010).
15. Whitea, S.D., Kohlenbach, P. and Bongs, C. "Indoor temperature variations resulting from solar desiccant cooling in a building without thermal backup", Int. J. Refrig., 32, pp. 695-704 (2009).

16. Halliday, S.P., Beggs, C.B. and Sleigh, P.A. "The use of solar desiccant cooling in the UK: a feasibility study", Appl. Therm. Eng., 22, pp. 1327-1338 (2002).

17. White, S.D., Kohlenbach, P. and Bongs, C. "Indoor temperature variations resulting from solar desiccant cooling in a building without thermal backup", Int. J. Refrig., 32, pp. 695-704 (2009).

18. Davagere, B.S., Sherif, S.A. and Goswami, D.Y. "A feasibility study of a solar desiccant air conditioning system - Part II: transient simulation and economics", Int. J. Energ. Res., 23, pp. 103-166 (1999).

19. Filiz, O., Mehmet, E. and Hikmet, E. "Experimental investigation of thermal performance of a doubleflow solar air heater having aluminum cans", Renew. Energ., 34, pp. 2391-2398 (2009).

20. Hikmet, E., Filiz, O., Mehmet, E. and Abdulkadir, S. "Modeling of a new solar air heater through leastsquares support vector machines", Expert. Syst. Appl., 36, pp. 10673-10682 (2009).

21. Ahmed, A., Pasaran, P. and Wipe, X.B. "Use of unglazed transpired solar collectors for desiccant", Sol. Energy, 62, pp. 1-9 (1998).

22. Bourdoukan, P., Wurtz, E., Joubert, P. and Sperandio, M. "Potential of solar heat pipe vacuum collectors in the desiccant cooling process: modeling and experimental results", Sol. Energy, 82, pp. 1209-1219 (2008).

23. Solar Energy Laboratory, U.o.W.-M. TRNSYS 16, a TRaNsient SYstem Simulation program, http:// www.wisc.edu.

24. Ge, T.S., Li, Y., Wang, R.Z. and Dai, Y.J. "A review of the mathematical models for predicting rotary desiccant wheel", Renew. Sust. Energ. Rev., 12, pp. 1485-528 (2008).

25. Nayak, S.M. "Experimental and theoretical investigation of integrated engine generator-liquid desiccant system", PhD Thesis, College Park, University of Maryland, United States (2005).

26. Kang, T.S. and Maclaine-Cross, I.L. "High performance, solid desiccant, open cooling cycles", J. Sol. Energ. Eng., 111, pp. 176-183 (1989).

27. Collier, R.K., Barlow, R.S. and Arnold, F.H. "An overview of open-cycle desiccant-cooling systems and materials", J. Solar Energ. Eng., 104, pp. 28-34 (1982).

28. La, D., Dai, Y.J., Li, Y., Wang, R.Z. and Ge, T.S. "Technical development of rotary desiccant dehumidification and air conditioning: A review", Renew. Sust. Energ. Rev., 14, pp. 130-147 (2010).

29. Khoukhi, M. "The use of desiccant cooling system with IEC and DEC in hot-humid climates", Int. J. Energ. Eng., 3, pp. 107-111 (2013).

30. NovelAire Technologies Heat \& Mass Transfer Products, http//www.novelaire.com. 
31. Camargo, J.R., Ebinuma, C.D. and Silveira, J.L. "Thermo economic analysis of an evaporative desiccant air conditioning system", Appl. Therm. Eng., 23, pp. 1537-1549 (2003).

32. ASHRAE, ASHREA Handbook, HVAC systems and Equipments (2008).

33. Ahmadzadehtalatapeh, M. "Performance study of a solar integrated central heating system of a residential building using TRNSYS- an hourly simulation model", Int. J. of Eng.: Aspects, 27, pp. 457-466 (2014).

34. ASHRAE, ASHRAE Handbook, HVAC Applications (SI) (2007).

\section{Biography}

Mohammad Ahmadzadehtalataeph received BSc and MSc degrees in Mechanical Engineering from Tabriz University and Ferdowsi University of Mashhad, Iran in 2000 and 2002, respectively. He obtained his $\mathrm{PhD}$ in Mechanical Engineering in 2011 from the University of Malaya, Malaysia. He is currently an Assistant Professor in the Chabahar Maritime University, Iran. His research interest areas are energy saving in buildings, renewable energy systems, heat pipe heat exchangers, and air-conditioning systems. 